\title{
Abundances of Jupiter's Trace Hydrocarbons From Voyager and Cassini
}

\author{
C.A. $\operatorname{Nixon}_{a, b}$, R.K. Achterberg $a, b$, P.N. Romani $b$, M. Allen ${ }_{c, d}$, \\ X. Zhang, N.A. Teanby, P.G.J. Irwin, , F.M. Flasar ${ }_{b}$ \\ * Corresponding author: e-mail: conor.a.nixon@nasa.gov \\ ${ }_{a}$ University of Maryland, College Park, MD 20742, USA \\ ${ }_{b}$ NASA Goddard Space Flight Center, Greenbelt, MD 20771, USA \\ ${ }_{c}$ California Institute of Technology, Pasadena, CA 91125 \\ ${ }_{d}$ Jet Propulsion Laboratory, 4800 Oak Grove Drive, Pasadena, CA 91109 \\ ${ }_{e}$ Atmospheric, Oceanic and Planetary Physics, University of Oxford, Clarendon Laboratory, \\ Parks Road, Oxford, OX1 3PU, UK
}

Accepted for publication in Planetary and Space Science, May 172010

doi $10.1016 /$ j.pss2010.05.08

(figures $=12$ tables $=5$ ) 
1 Running Head:

\section{Jupiter's Hydrocarbon Abundances}

3 Direct correspondence to:

4 Conor A. Nixon

${ }_{5}$ Solar System Exploration Division

6 Planetary Systems Laboratory - Code 693

7 NASA Goddard Space Flight Center

\& Greenbelt

9 $\mathrm{MD} 20771$

${ }_{10}$ U.S.A.

${ }_{11}$ tel. (301) 286-6757

12 fax. (301) 286-0212 


\section{ABSTRACT}

The flybys of Jupiter by the Voyager spacecraft in 1979, and over two decades later by Cassini in 2000, have provided us with unique datasets from two different epochs, allowing the investigation of seasonal change in the atmosphere. In this paper we model zonal averages of thermal infrared spectra from the two instruments, Voyager 1 IRIS and Cassini CIRS, to retrieve the vertical and meridional profiles of temperature, and the abundances of the two minor hydrocarbons, acetylene $\left(\mathrm{C}_{2} \mathrm{H}_{2}\right)$ and ethane $\left(\mathrm{C}_{2} \mathrm{H}_{6}\right)$. The spatial variation of these gases is controlled by both chemistry and dynamics, and therefore their observed distribution gives us an insight into both processes. We find that the two gases paint quite different pictures of seasonal change. Whilst the 2-D crosssection of $\mathrm{C}_{2} \mathrm{H}_{6}$ abundance is slightly increased and more symmetric in 2000 (northern summer solstice) compared to 1979 (northern fall equinox), the major trend of equator to pole increase remains. For $\mathrm{C}_{2} \mathrm{H}_{2}$ on the other hand, the Voyager epoch exhibits almost no latitudinal variation, whilst the Cassini era shows a marked decrease polewards in both hemispheres. At the present time, these experimental findings are in advance of interpretation, as there are no published models of 2-D Jovian seasonal chemical variation available for comparison.

key words=JUPITER ATMOSPHERE; ATMOSPHERIC ABUNDANCES, OUTER PLANETS; INFRARED SPECTROSCOPY; ABUNDANCE RETRIEVAL 


\section{Introduction}

The Voyager 1 and 2 encounters with Jupiter of March and July 1979 (jovian northern fall equinox) offered the first opportunities to map Jupiter in the thermal infrared with a latitude resolution of better than $10^{\circ}$ - then unobtainable from the ground - and a spectral resolution sufficient to measure the abundances of trace gas species. The tool for this mapping was IRIS (the InfraRed Interferometer and Spectrometer, Hanel et al., 1977), and trace gases of interest included ethane $\left(\mathrm{C}_{2} \mathrm{H}_{6}\right)$ and acetylene $\left(\mathrm{C}_{2} \mathrm{H}_{2}\right)$ - secondary species derived from photolysis of the primary carbon-bearing molecule, methane $\left(\mathrm{CH}_{4}\right)$. Although some preliminary findings were published in a conference report (Maguire et al., 1984), a full radiative transfer model was never applied to retrieve a meridional trend in the abundances.

Two decades later, the Cassini spacecraft swung by Jupiter in a distant flyby maneuver $\left(137 R_{J}\right)$ en route to Saturn. The official encounter period, during which time observations were made, lasted six months symmetric about the closest approach on December 30th 2000 (northern summer solstice). Carrying on board the Composite Infrared Spectrometer (CIRS), Cassini was able to re-map the planet in the thermal infrared, achieving a spatial resolution comparable to Voyager IRIS but with much higher maximum spectral resolution $\left(0.48 \mathrm{~cm}^{-1}\right.$, versus $3.9 \mathrm{~cm}^{-1}$ for IRIS, full width to half maximum (FWHM)). Meridional trends of stratospheric and tropospheric $\mathrm{C}_{2} \mathrm{H}_{2}$ and $\mathrm{C}_{2} \mathrm{H}_{6}$ have been retrieved from CIRS data acquired during December 1-15 2000 prior to cloest approach, by Nixon et al. (2007) (hereafter Paper I).

The abundances of the minor hydrocarbons are important because these species serve as tracers of atmospheric circulation. The photochemical lifetime of ethane in the stratosphere $\left(3 \times 10^{10} \mathrm{~s}\right.$ at $\left.5 \mathrm{mbar}\right)$ is significantly greater than one Jovian year $\left(3.7 \times 10^{8} \mathrm{~s}\right)$, whereas the acetylene lifetime $\left(5 \times 10^{7} \mathrm{~s}\right.$ at $\left.5 \mathrm{mbar}\right)$ is substantially shorter. Note that the 
solar cycle $\left(3.4 \times 10^{8} \mathrm{~s}\right)$ which affects the photochemistry almost equals the Jovian year. In the presence of dynamical motions on seasonal timescales, the meridional abundance trend in a relatively short-lived species (such as acetylene) is expected to show significant change, whereas a long-lived species (ethane) should present a more constant distribution. The logical means of testing this hypothesis is to intercompare the hydrocarbon abundances using the datasets of Voyager and Cassini, which encountered Jupiter at two different seasons: near northern fall equinox, and 1.75 jovian years later just after northern summer solstice.

Such a comparison is the objective of this paper. We begin by analyzing the Voyager spectra, retrieving for the first time with a full radiative transfer modeling approach the meridional abundance trends of ethane and acetylene in 1979. We also reanalyze the CIRS dataset, using a significantly revised spectroscopic atlas for ethane (Vander Auwera et al., 2007) that was published since the first Cassini jovian hydrocarbons paper appeared (and is also used the IRIS data analysis here). The intensities of this new list are revised upwards by some 44\% relative to the GEISA 2003 list used in Paper I, resulting in a corresponding decrease in abundances. We then proceed to compare the abundance profiles at the two epochs (northern fall in 1979 versus summer in 2000) discussing the implications and drawing conclusions.

\section{Data Acquisition}

\subsection{Cassini CIRS Observations}

The Casini CIRS instrument is a dual interferometer, with a mid-IR Michelson interferometer covering the range $600-1400 \mathrm{~cm}^{-1}$, and a far-IR polarizing interferometer covering the range $10-600 \mathrm{~cm}^{-1}$ (Flasar et al., 2004). The spectra analyzed here have 
been selected in the same way as in Paper I (described below), the only difference being that they are derived from a later version of the CIRS database. This has some improvements to the calibration algorithm, including rejection of some 'bad' spectra (scan mechanism out of phase lock) and greater suppression of numerical artifacts from the Fourier transform. These mid-IR spectra were acquired at the highest spectral resolution of CIRS (0.48 $\mathrm{cm}^{-1}$ FWHM, Hamming apodized) during December 1-15 2000, and cover a latitude range of $70^{\circ} \mathrm{S}$ to $70^{\circ} \mathrm{N}$ with a spatial resolution of $6.0-3.5^{\circ}$ great circle arc. The spectra were binned in $5^{\circ}$ bins, and with auroral areas excluded as before. The effective emission angle $\bar{\theta}$ for the $i^{\text {th }}$ bin was computed from the mean of the airmass (plane parallel atmosphere) of the $N_{j}$ spectra as follows:

$$
\bar{\theta}_{i}=\operatorname{arcsec}\left[\frac{1}{N_{j}} \sum_{j=1}^{N_{j}} \sec \left(\theta_{j}\right)\right]
$$

For further details see Table I.

\section{[TABLE I appears here]}

\subsection{Voyager IRIS Observations}

The two Voyager spacecraft passed much closer to Jupiter than Cassini $\left(5.7 \times 10^{5} \mathrm{~km}\right.$ versus $9.8 \times 10^{6} \mathrm{~km}$ ). The IRIS spectrometer carried on board was also a Michelson type like the mid-infrared of CIRS - but with a single bolometer detector instead of two $1 \times 10$ arrays. The IRIS spectra selected here are from the Voyager 1 inbound north/south map, taken over a 10.5 hour period beginning 2 days, 13 hours before closest approach at a range between $2.9 \times 10^{6}$ and $3.6 \times 10^{6} \mathrm{~km}$. Nevertheless, the much larger field of view (FOV) of the IRIS bolometer $(4.36 \mathrm{mrad})$ versus the CIRS mid-IR detectors $(0.29 \mathrm{mrad}$ Nixon et al., 2009b) results in slightly larger projected field of view on the disk of 10 to 12 degrees of latitude at disk center. The observation was made by repeatedly stepping 
the field of view from north to south along Jupiter's central meridian, with the rotation of Jupiter providing longitude coverage. The spectra were then averaged in $10^{\circ}$ wide latitude bins, stepped every $5^{\circ}$. As the spectra were acquired at constant airmass for each latitude, the emission angles were simply averaged in each bin. See Table II for details.

\section{[TABLE II appears here]}

\section{Data Analysis}

\subsection{Model Atmosphere}

The model atmosphere used by us is identical to that of Paper I. The initial temperature profile was taken from the Galileo probe ASI measurements (Seiff et al., 1998), from 4 bar to $0.4 \times 10^{-6}$ bar. Hydrogen and helium have uniformly mixed vertical abundances (0.863 and 0.134 respectively) (Niemann et al., 1998; von Zahn et al., 1998). Initial vertical abundance profiles for the three hydrocarbons $\left(\mathrm{CH}_{4}, \mathrm{C}_{2} \mathrm{H}_{6}\right.$ and $\left.\mathrm{C}_{2} \mathrm{H}_{2}\right)$ were computed using a photochemical model, described in Paper I. Solar maximum conditions were used for the UV flux in this calculation for both the Cassini and Voyager epochs, as both encounters occured at similar points near the maximum in the solar cycle.

The vertical profiles for the known constituents ammonia and phosphine were controlled by a three-parameter model: (1) deep abundance; (2) 'knee' pressure level, the transition level from deep, fixed, to varying abundance; (3) a fractional scale height used to decrease the abundance above the 'knee' level. The retrieval of ammonia and phosphine parameters from the mid-infrared spectrum has been discussed extensively elsewhere (Irwin et al., 2004; Abbas et al., 2004; Fouchet et al., 2004; Achterberg et al., 2006). As these gases are not our focus here, we will remark only briefly on them concerning their effect on the hydrocarbon retrievals. 
With regard to $\mathrm{PH}_{3}$, the spectral effect of the $\nu_{4}$ band $\left(1121 \mathrm{~cm}^{-1}\right)$ is significant in the region $900-1200 \mathrm{~cm}^{-1}$ (see Fig. 1 of Irwin et al. (2004)) and insignificant outside, including the hydrocarbon spectral ranges considered here. Therefore its parameters were fixed at the values $\left(6 \times 10^{-7}, 1.0\right.$ bar, 0.3) recommended by Irwin et al. (2004). Regarding $\mathrm{NH}_{3}$, the spectral effect of the $\nu_{2}$ band at $950 \mathrm{~cm}^{-1}$ is most significant from $\sim 800-1000 \mathrm{~cm}^{-1}$ (although the effects range from $750-1200 \mathrm{~cm}^{-1}$ ), and so primarily affects the ethane spectral range. As it varies with latitude, it must be included in the retrieval. For our purposes the knee pressure was fixed at 0.7 bar and the both the deep pressure and fractional scale height were included as free parameters, with a priori values of $(2.2 \pm$ $0.22) \times 10^{-4}$ and $0.15 \pm 0.05$ respectively. Note also that ammonia is entirely separable from ethane due to the very different spectral signature. For discussion of the latitude and longitude variation of these retrieved parameters, see the above-referenced papers.

Fig. 1 depicts the model atmosphere, which is divided into 71 vertical layers.

Fig. 1. Appears Here.

\subsection{Forward Spectral Model and Retrieval Algorithm}

The computation of the spectrum from the model atmosphere was carried out using the Nemesis computer code (Irwin et al., 2008), which also accomplishes the fitting and parameter retrieval. This code has been significantly validated in the past, having been successfully applied to model reflection and thermal infrared spectra of Venus, Mars, Jupiter, Saturn and Uranus; from a variety of spacecraft and ground-based facilities and instruments, including Galileo, Cassini, Mars Express, Venus Express, UIST.

The Jovian model opacity is derived from two sources: (i) gas vibrational-rotational bands, and (ii) collisional-induced gas opacity. Jupiter's atmosphere is also known to contain stratospheric haze. The addition of haze (particulate) opacity was investigated 
in paper I using the refractive index co-efficients of Khare et al. (1984) or a simple grey absorber. However, the effect on the retrieval was not found to be statistically significant, i.e. the difference to the $\chi^{2}$ was below the noise threshold. Therefore we have followed the approach of Paper I and do not include a haze opacity in our retrievals. The atlases for the gas bands are identical to Paper I, except for ethane, where we substituted the more recent, improved list of Vander Auwera et al. (2007), now also available in HITRAN 2008 (Rothman et al., 2009) and the 2009 update of GEISA (Jacquinet-Husson et al., 2008). The collision-induced opacity uses the method of Borysow and co-workers (Borysow et al., 1985, 1988).

The spectral calculation proceeds based on the correlated- $k$ approximation (Goody et al., 1989), whereby tables of $k$-coefficients are pretabulated in advance, at an appropriate range of pressure and temperature grid points covering the entire atmospheric range of interest. The spectral resolution was convolved into the $k$-tables during the computation, so that separate tables were built for each gas at both the IRIS and CIRS resolutions: 3.9 and $0.48 \mathrm{~cm}^{-1}$ FWHM of Hamming function instrument line shape (ILS) respectively (see Nixon et al., 2009a, section 2.2 for further details of the apodization). This constitutes a change and improvement over the spectral modeling of Paper I, where the ILS was approximated by a triangle function, and is one source of the slight differences seen in the retrieved abundance of $\mathrm{C}_{2} \mathrm{H}_{2}$ from the Cassini CIRS spectra. See further discussion in $\$ 5.1$.

The fitting of the spectrum to the data was achieved through the formalism of Rodgers (2000), known as non-linear least squares optimal estimation. In essence, this is similar to minimizing the reduced $\chi^{2}$ difference between the model and data. However the goodness-of-fit measure, known as the cost function $\phi$, additionally includes a constraint (or smoothing term) from a priori (assumed) information about the likely range of values that the parameters can take. The cost function is therefore the quadratic sum of 
the spectral $\chi^{2}$, plus a similar term that measures the deviation of the solution from the a priori constraint (see $\$ 4.2$ of Paper I). $\phi$ is minimized using the Levenburg-Marquart technique (Press et al., 1992), along downhill gradients computed by taking the numerical partial derivatives of the solution vector (computed spectrum) with respect to the free parameters - also known as the functional derivatives. The retrieval terminates when a pre-set convergence limit is reached, in this case when the change in the cost function is less than $0.2 \%$ between iterations. For further details regarding the Nemesis algorithm, see Irwin et al. (2008).

\subsection{Vertical sensitivity from functional derivatives}

Before commencing on the retrievals, we first used the forward model to investigate the vertical regions of information, by computing the functional derivatives $\delta I / \delta x_{i, j}$ of the radiance $I$ for each of the $x_{i}$ parameters at each level $j$ in the model atmosphere. The functional derivatives for the $0.48 \mathrm{~cm}^{-1}$ resolution Cassini CIRS spectra are described in Paper I, so we here describe the corresponding computations for the lower resolution $\left(3.9 \mathrm{~cm}^{-1}\right)$ Voyager IRIS spectra, noting differences from the CIRS sensitivities.

Fig. 2. Appears Here.

Figs. 2 shows the functional derivatives for temperature in two spectral regions: in the hydrogen $\mathrm{S}(1)$ continuum at $600-650 \mathrm{~cm}^{-1}$ sensitive to the upper troposphere $(\sim 200$ mbar), and in the $\mathrm{P}$ and $\mathrm{Q}$ branches of the methane $\nu_{4}$ band at $1260-1310 \mathrm{~cm}^{-1}$. The latter are sensitive to several altitude regions: 1-15 mbar in the middle stratosphere, but also at $\sim 7 \mu$ bar in the upper stratosphere due to the optically thick center of the Qbranch at $1305 \mathrm{~cm}^{-1}$. Therefore, by fixing the abundances of $\mathrm{H}_{2}$ and $\mathrm{CH}_{4}$, we can sound the temperature structure at three different vertical levels.

Figs. 34 show the functional derivatives for the gases $\mathrm{C}_{2} \mathrm{H}_{2}$ and $\mathrm{C}_{2} \mathrm{H}_{6}$. Acetylene has a 
broad sensitivity of about 0.1-7 mbar in the stratosphere, but also has absorption at 300800 mbar in the troposphere. Similarly, ethane has a range of 1-10 mbar the stratosphere, and 100-700 mbar in the troposphere.

Fig. 3. Appears Here.

Fig. 4. Appears Here.

Fig. 5 summarizes the vertical sensitivity ranges of Voyager IRIS, and compares these values to those of Cassini CIRS, both calculated at the equator. See also Table III. The most important difference is that the hotband of $\mathrm{C}_{2} \mathrm{H}_{2}$ at $\sim 731 \mathrm{~cm}^{-1}$, about $1 \mathrm{~cm}^{-1}$ in width, is resolved at the CIRS but not at the IRIS spectral resolution. Therefore, the elevated range of sensing for CIRS at $731 \mathrm{~cm}^{-1}$ (peak at 0.1 mbar, FWHM extending to 0.01 mbar) relative to the $\nu_{5}$ Q-branch at $729 \mathrm{~cm}^{-1}$ (peak at 5 mbar, FWHM to 0.03 mbar) is lost. Fig. 6 and Table IV show similar information, but calculated at $58^{\circ} \mathrm{N}$ showing that the sensitivity ranges shift slightly with latitude.

\section{[TABLE III appears here]}

Fig. 5. Appears Here.

\section{[TABLE IV appears here]}

Fig. 6. Appears Here.

Before leaving this topic, we also must consider whether the vertical retrieval range will be limited by the transition from local thermodynamic equilibrium (LTE) to nonLTE (NLTE) conditions. For the case of Jupiter's methane at least, the problem has been previously considered by Halthore et al. (1994), who investigated the relaxation of dilute gaseous methane in bulk hydrogen. In that paper, the authors used a room temperature measurement for the collisional de-excitation time $\tau_{\mathrm{C}}=C_{10}^{-1}$ for the $\nu_{3}$ band of methane $(3.3 \mu \mathrm{m})$ in combination with a Landau-Teller formula to extrapolate the relaxation to the ground state under Jovian conditions. The same $\tau_{\mathrm{C}}$ also applies to the $\nu_{4}$ band, as there 
is fast transfer of vibrational energy $(\mathrm{V}-\mathrm{V})$ between these excitations. Their Equation 5 may be re-arranged:

$$
\tau_{\mathrm{C}}=2.3175 \times 10^{-7} p^{-1} \exp \left(40 T^{-1 / 3}\right)
$$

where $p$ is pressure in Torr and $T$ is temperature in K. In Fig. 7 we compare the altitudevariation of $\tau_{\mathrm{C}}$ calculated for our initial equatorial atmosphere, versus the spontaneous emission timescale $\tau_{\mathrm{A}}=A_{10}^{-1}$, taken as $0.4 \mathrm{~s}$ following Halthore et al. (1994). We find that $\tau_{\mathrm{A}} \simeq \tau_{\mathrm{C}}$ at a pressure of $\sim 0.8 \mu$ bar. We have also made an independent estimate of $A_{10}$ by averaging across the $\mathrm{CH}_{4} \nu_{4}$ band in HITRAN from $1215-1315 \mathrm{~cm}^{-1}$, arriving at an even longer timescale of $1.7 \mathrm{~s}$, putting the transition level well above the upper pressure limit our model atmosphere. The variation with latitude is small (using the profiles derived later in this paper). Therefore we conclude that our temperature retrievals are valid over the range indicated by the contribution functions, which probe pressures $p>0.8 \mu$ bar.

Fig. 7. Appears Here.

\section{Results}

The retrieval proceeded in the following two-step manner. Firstly, each latitudinal average spectrum was analyzed to retrieve temperatures in the troposphere and stratosphere, using spectral portions of the hydrogen continuum (600-670 $\mathrm{cm}^{-1}$ and $\left.760-800 \mathrm{~cm}^{-1}\right)$ and methane $\nu_{4}$ band $\left(1225-1325 \mathrm{~cm}^{-1}\right)$. Secondly, the temperature profile was fixed and the gas abundances of $\mathrm{C}_{2} \mathrm{H}_{2}$ and $\mathrm{C}_{2} \mathrm{H}_{6}$ allowed to vary, and their vertical distributions retrieved from their bands at $670-760 \mathrm{~cm}^{-1}\left(\mathrm{C}_{2} \mathrm{H}_{2} \nu_{5}\right)$ and $800-850 \mathrm{~cm}^{-1}\left(\mathrm{C}_{2} \mathrm{H}_{6} \nu_{9}\right)$.

Note that for reference, the retrieved 2-D temperature fields, gas mixing ratios for $\mathrm{C}_{2} \mathrm{H}_{2}$ and $\mathrm{C}_{2} \mathrm{H}_{6}$, and formal errors on these quantities, from both datasets (Voyager and Cassini epochs), have been archived on-line. See http://hdl.handle.net/2014/41479 
and http://hdl.handle.net/2014/41480. For this reason, extensive tables of numeric quantities and errors are not enumerated in this paper, while some selected values are discussed in context.

\subsection{Temperatures}

Fig. 8. Appears Here.

Fig. 8 shows the retrieved temperatures for Voyager IRIS (top), Cassini CIRS (middle) and the difference (bottom). Considering first the stratosphere at 1 mbar, we see that the northern hemisphere has warmed considerably $(\sim 5 \mathrm{~K})$ at this epoch, equivalent to 1.75 Jovian years later. Overall, the Cassini lower stratosphere exhibits a more pronounced hemispheric asymmetry than the Voyager era, however the upper stratosphere (0.01 mbar) is colder $(\sim-10 \mathrm{~K})$. Evidence for seasonal change is less apparent in the troposphere at 100-400 mbar, as expected due to the much greater thermal inertia at these levels.

Note that the upper stratosphere region (0.01 mbar) was not considered in the earlier analysis of Simon-Miller et al. (2006), who also compare retrieved Jovian temperatures from Voyager and Cassini with an emphasis on derivation of wind fields. These authors used a different set of Cassini maps (from early January 2001) at lower $\left(2.8 \mathrm{~cm}^{-1}\right)$ spectral resolution than our selection $\left(0.48 \mathrm{~cm}^{-1}\right)$, although with higher spatial sampling in latitude and longitude. Where our results overlap those of Simon-Miller et al. (2006), the agreement is good (see their Fig. 2).

We also see evidence for the the so-called jovian 'Quasi-Quadrennial Oscillation' (QQO), a cyclic temperature variation, most prominent in the lower stratosphere, that appears to observe an approximately four (terrestrial) year period, and may be analogous to the Earth's quasi-biennial oscillation (QBO, 26 month period). See Fig. 8 (c), at 20 mbar and $10^{\circ} \mathrm{S}$, where a localized increase in temperature of $\sim 8 \mathrm{~K}$ is apparent. The four-year 
periodicity cannot be inferred from these two widely-spaced epochs alone, but when the time series of equatorial stratospheric temperatures is plotted with higher temporal resolution, e.g. Fig. 4 of Simon-Miller et al. (2006), the pattern becomes apparent. The four-year cycle is not exact (hence 'quasi'): periodogram analysis by Simon-Miller et al. (2006) indicates two peaks with periodicities of 3.5 and 4.3 years. Leovy et al. (1991) have suggested that the QQO is caused by the stresses induced by vertically-propagating waves. For further details and discussion see Leovy et al. (1991); Friedson (1999); Moses et al. (2004); Simon-Miller et al. (2006).

\subsection{Gas abundances}

The corresponding contour maps for the hydrocarbon abundances are shown in Figs. 9 and 10. Note that the vertical range of $\mathrm{C}_{2} \mathrm{H}_{2}$ derived from CIRS data has been cut to match the smaller vertical range of IRIS (see 33.3 ).

Fig. 9. Appears Here.

The $\mathrm{C}_{2} \mathrm{H}_{2}$ difference plot (Fig. 9 (c)) shows the most dramatic difference, with the polar stratospheric abundances dropping at 1-10 mbar, and more intensely in the south than the north. This is also evident in Fig. 9 (b), where the upward-curved contours contrast markedly with the more level contours of Fig. 9 (a).

Fig. 10. Appears Here.

Ethane, in contrast, shows a much smaller change from Voyager to Cassini, although the Cassini era appears to have a more uniform stratospheric distribution, whereas the Voyager period is characterized by a positive bias towards the north. Also, the CIRS epoch shows systematically higher abundances over much of the atmosphere. 


\section{Discussion}

\subsection{Comparison to Paper I}

Fig. 11. Appears Here.

The first reference point for this study is the previously published retrievals of hydrocarbon abundances from CIRS data (Paper I). The deviation between the present work and Paper I is plotted in Fig. 11, For $\mathrm{C}_{2} \mathrm{H}_{2}$, the results are almost identical in regions where the information content is maximum, e.g. at 2 mbar in the equatorial stratosphere the change is just 1\%, and at 300 mbar in the equatorial troposphere the change is $10 \%$. The maximum change was at $62^{\circ} \mathrm{S}, 300$ mbar where the deviation reached $25 \%$. These differences are well within the overall error bars of $\sim 40-50 \%$, and may be attributed to small changes in the modeling method, such as the improved instrumental line shape (see \$3.2). See on-line data for full data and errors (\$4).

For $\mathrm{C}_{2} \mathrm{H}_{6}$, the change at 5 mbar in the equatorial stratosphere was $40 \%$, with a $20 \%$ change at 300 mbar. However, these differences are relative to smaller error bars of 15$20 \%$, and are therefore clearly significant. These changes can be explained by the new line list used for $\mathrm{C}_{2} \mathrm{H}_{6}$ (see $\$ 3.2$ ), which has higher line intensities than used in Paper I, by some $44 \%$ over the whole band.

\subsection{Comparison to other previous studies}

In the recent review on the Jovian stratosphere by Moses et al. (2004, $§ 7.2 .3)$, describes the history of abundance measurements of $\mathrm{C}_{2} \mathrm{H}_{2}$ and $\mathrm{C}_{2} \mathrm{H}_{6}$ in the Jovian nonauroral stratosphere, spanning the period from 1973 to 1997. Their Table 7.1 lists all major observational measurements, totaling 19 published studies in all, broken down into 
16 of $\mathrm{C}_{2} \mathrm{H}_{2}$ and 23 of $\mathrm{C}_{2} \mathrm{H}_{6}$. These varied researches cover Jupiter's stratosphere, mainly at low latitudes, but encompassing every season, and at pressures from 80 to 0.005 mbar.

In light of the present findings, it is now clear that Jupiter's stratosphere is a dynamic environment that exhibits seasonal change in the abundances of the trace hydrocarbons at all latitudes and pressure levels. Therefore, direct comparison between our findings and these previous studies is not universally appropriate. Clearly, the most meaningful way to proceed is to compare results obtained at similar seasons to the results we have obtained for the Cassini and Voyager epochs. Table V compares a relevant subset of observations, taken from Moses et al. (2004, Table 7.1), that apply to the same season as either the Voyager or Cassini encounters. We have added error bars where those were available in the original sources.

\section{[TABLE V appears here]}

Relative to our Cassini results, we found only one applicable comparison, for $\mathrm{C}_{2} \mathrm{H}_{6}$ only, which is the study of Livengood et al. (1993) based on data from 12/89, about 1 full Jovian year before Cassini. The Cassini-derived value of $(9.4 \pm 1.8)$ ppm at $1 \mathrm{mbar}$ is somewhat greater their value of $(3.6 \pm 1.3) \mathrm{ppm}$, at $0.3-3 \mathrm{mbar}$, similar to our conclusion in Paper I. We note however that we would achieve agreement at their lower bound of 3 mbar where we find an ethane VMR of $(4.8 \pm 0.8) \mathrm{ppm}$. The other studies for $\mathrm{C}_{2} \mathrm{H}_{6}$ in the 4-5 mbar region also agree with our results when the respective error bars are considered. Note that the entire set of past measurements for $\mathrm{C}_{2} \mathrm{H}_{6}$ is generally self-consistent, in marked contrast to those of $\mathrm{C}_{2} \mathrm{H}_{2}$, discussed hereafter.

With regard to $\mathrm{C}_{2} \mathrm{H}_{2}$, our results are compatible with those of Owen et al. (1980) (10 mbar) and Noll et al. (1986) (3 mbar). We find about 1 order of magnitude less $\mathrm{C}_{2} \mathrm{H}_{2}$ at 10 mbar than Clarke et al. (1982) and Gladstone and Yung (1983), though 1 order of magnitude greater than Bezard et al. (1995). Note that the prior results at 10 mbar are 
mutually inconsistent. The reason for this is unclear, but the lower abundance compared to $\mathrm{C}_{2} \mathrm{H}_{6}$ may be partly responsible. At 1 mbar, our result appears to be compatible with Bezard et al. (1995), if some error is allowed on those results.

\subsection{Chemistry and Dynamics}

The meridional distribution of a gas species depends upon the relative chemical and transport lifetimes. In the absence of meridional transport, for a species that is shortlived photochemically (compared to seasonal time-scales) we expect that the observed distributions in latitude should, to first order, follow the incident seasonal insolation. This was noted in Paper I for $\mathrm{C}_{2} \mathrm{H}_{2}$, whose lifetime is short $\left(3 \times 10^{7} \mathrm{~s}\right.$ at 5 mbar $)$ compared to both a Jovian season $\left(1 \times 10^{8} \mathrm{~s}\right)$, and the inferred timescale for meridional mixing from analysis of Comet Shoemaker-Levy 9 debris $\left(6 \times 10^{8} \mathrm{~s}\right.$, Lellouch et al., 2002).

For species with photochemical lifetimes approaching seasonal time-scales, a phase lag in response to the insolation is expected with a diminished peak to peak variation in the mixing ratio. And finally for long lived species (e.g. ethane, with lifetime $3 \times 10^{10} \mathrm{~s}$ at 5 mbar) only small perturbations about annual global averages are expected. Meridional transport will wash out any differences. Additionally the vertical transport required to close the meridional cells will cause changes in the mixing ratios at various pressures depending upon the vertical profile of the mixing ratio, e.g. vertical transport bringing down $\mathrm{C}_{2} \mathrm{H}_{2}$ rich air to a given pressure level.

Figure 12 compares the photochemical lifetimes (halving and doubling) for $\mathrm{C}_{2} \mathrm{H}_{2}$ and $\mathrm{C}_{2} \mathrm{H}_{6}$ from the 1-D model calculations described in Paper I to the Jovian year, the solar cycle, and the eddy mixing time $\left(\mathrm{H}^{2} / \mathrm{K}\right.$, where $\mathrm{H}$ is the mixed atmospheric scale height and $\mathrm{K}$ is the eddy diffusion coefficient). The acetylene lifetimes are less than the seasonal, solar cycle, and eddy mixing times, while the opposite is the case for ethane. In the 
model both the acetylene and ethane mixing ratios increase with decreasing pressure, so downward transport of air parcels will increase their relative abundances and conversely for rising parcels. However, ethane is much more uniformly mixed with height due to its chemical lifetimes being longer than the eddy transport time. Thus vertical transport will have more of an effect on the $\mathrm{C}_{2} \mathrm{H}_{2}$ mixing ratio than for ethane, as enriched air is downwardly advected.

Fig. 12. Appears Here.

For acetylene and equinoctial conditions, we expect a more symmetric distribution compared to solsticial. Our results seem to validate this hypothesis, as the Voyager distribution of $\mathrm{C}_{2} \mathrm{H}_{2}$ appears much more symmetric than the Cassini distribution, which is biased towards the northern hemisphere - as expected for northern fall equinox and summer solstice conditions respectively. For ethane, the reverse is seen: the Cassini (solstice) epoch shows a more uniform latitude distribution than the Voyager (equinox) epoch, which may indicate a phase lag between dynamics and seasons.

The higher abundances of $\mathrm{C}_{2} \mathrm{H}_{6}$ seen at most latitudes by CIRS may in part be due to the increased mean insolation at northern solstice relative to fall equinox: Jupiter was $5 \%$ closer to the Sun in December 2000 compared to March 1979, resulting in 10\% higher solar flux (21\% flux variation possible due to solar distance over an entire year). In addition, we note that the increase in $\mathrm{C}_{2} \mathrm{H}_{6}$ towards the poles at both epochs may be partially due to particle-induced auroral chemistry (Yelle et al., 2001).

\subsection{Comparison to Saturn}

Our findings for Jupiter closely parallel recent studies of the minor hydrocarbons in Saturn's atmosphere, which have mostly found a decrease in acetylene and constant or increasing ethane from equator to pole. Howett et al. (2007), using Cassini CIRS data, 
found a decrease in the abundance of $\mathrm{C}_{2} \mathrm{H}_{2}$ at 2 mbar from $30-68^{\circ} \mathrm{S}$ by a factor 1.8 , although there was an initial increase from $18-30^{\circ} \mathrm{S}$. Ethane on the other hand increased from the equator to the south pole by 2.5. Hesman et al. (2009), combining results from Cassini CIRS and ground based spectroscopy with the IRTF and Celeste, found a decrease in $\mathrm{C}_{2} \mathrm{H}_{2}$ by a factor 2.7 from $5-75^{\circ} \mathrm{S}$, although there was a rise again at $87^{\circ} \mathrm{S}$. Ethane was constant from equatorial to southern mid-latitudes, where it began to rise in abundance, finally doubling at the south pole.

Both these studies used nadir-geometry spectra, limiting the range of vertical sensitivity. Guerlet et al. (2009) however have analyzed Cassini CIRS limb spectra to yield a more detailed vertical picture of the hydrocarbon meridional abundance variations. Acetylene is found to be sharply peaked at the equator at 1 mbar, with a gradual decrease through southern and northern mid-latitudes, while ethane is nearly flat from $50^{\circ} \mathrm{N}-50^{\circ} \mathrm{S}$, where is rises towards the south pole.

Overall, we see some intriguing similarities between the meridional variations of the secondary hydrocarbons on Jupiter and Saturn, although the details differ. The implication is that researches into understanding the origins of these distributions must proceed in parallel, and advances in understanding the mechanisms of one body are likely to improve our appreciation of the other. Note that on Saturn however we must be mindful of the effect of the ring shadow, which is seasonally varying over a 29.5 (earth) year period. This has the effect of shielding the low latitudes, reducing both the photolysis of methane, and the higher hydrocarbons, which must be accounted for correctly in photochmeical models. 


\section{Summary and Conclusions}

In this paper we have analyzed two infrared spectral datasets of Jupiter: (i) the Voyager IRIS dataset, pertaining to the northern fall equinox of 1979, and (ii) the Cassini CIRS dataset, taken near the northern summer solstice of 2000. We have modeled the spectra to retrieve, firstly atmospheric temperatures through the $\nu_{4}$ band of $\mathrm{CH}_{4}$ at $\sim 1305 \mathrm{~cm}^{-1}$, and secondly the abundances of $\mathrm{C}_{2} \mathrm{H}_{6}$ and $\mathrm{C}_{2} \mathrm{H}_{2}$ based on the derived temperatures. Our results extend from the upper troposphere to the upper stratosphere for temperature and $\mathrm{C}_{2} \mathrm{H}_{2}$ abundance, and cut-off slightly lower in the middle stratosphere for $\mathrm{C}_{2} \mathrm{H}_{6}$. The results comprise the first comprehensive 2-D comparison of the abundances of $\mathrm{C}_{2} \mathrm{H}_{2}$ and $\mathrm{C}_{2} \mathrm{H}_{6}$ in Jupiter's atmosphere at two different seasons. The results have been archived on-line for reference, as described in $\$ 4$

Our new findings confirm, improve and extend the results of our previous paper (Nixon et al., 2007). The distribution of $\mathrm{C}_{2} \mathrm{H}_{2}$ at the Cassini epoch is confirmed, whilst that of $\mathrm{C}_{2} \mathrm{H}_{6}$ is corrected, largely due to revised spectral line intensities published in the interim (Vander Auwera et al., 2007). We have also extended the Cassini distributions to a second Jovian season (Voyager), showing important similarities and differences.

For ethane, the 2-D distribution is quite similar, although we see that the Cassini picture is more symmetric than that of Voyager, where $\mathrm{C}_{2} \mathrm{H}_{6}$ is somewhat depleted in the north relative to the south. Also, the Cassini abundances are mostly higher overall, perhaps due to smaller solar distance. For acetylene the difference is much more dramatic, showing a uniform meridional profile at equinox, but strong depletions towards both poles at solstice. Therefore the solstice distribution seems to match the annual-mean picture that would be predicted by a 1-D photochemical model.

It is clear that Jupiter's stratosphere is indeed a complex environment, where chemistry 
415 is coupled to dynamics in ways that are poorly understood at present. Much additional 416 modeling work is required before these seasonal changes can be confidently interpreted, 417 and comprehensive radiative-dynamical-chemical models in two or three dimensions are ${ }_{418}$ urgently needed. The rewards of successful modeling of this data are large, and include 419 the significant advancement of our understanding not only of the Jovian atmosphere, but 420 also that of Saturn and the other outer planets as well. 


\section{Acknowledgements}

The acquisition of CIRS data is the result of the collective efforts of a large number of people, including the following who worked on various aspects of CIRS science planning, instrument commanding, uplink, calibration and databasing: S.B. Calcutt, R.C. Carlson, M.H. Elliott, E. Guandique, M. Kaelberer, V.G. Kunde, E. Lellouch, A. Mamoutkine, P.J. Schinder, M.E. Segura, J.S. Tingley, and also many engineers and science planners at the Jet Propulsion Laboratory. We would like to thank R.A. West, A.J. Friedson and Y.L. Yung for helpful discussions during the preparation of this manuscript. During the research for and writing of this report, RKA and FMF were funded by the NASA Cassini Project, and CAN and MA were supported by the NASA Outer Planets Research Program. Portions of this work were carried out by the Jet Propulsion Laboratory, under contract with the National Aeronautics and Space Administration. 


\section{References}

Abbas, M., LeClaire, A., Owen, T., Conrath, B., Flasar, F., Kunde, V., Nixon, C., Achterberg, R., Bjoraker, G., Jennings, D., Orton, G., Romani, P., 2004. Nitrogen isotopic ratio in Jupiter's atmosphere from observations by the Composite Infrared Spectrometer (CIRS) on the Cassini spacecraft. Astrophys. J. 602, 1063-1074.

Achterberg, R., Conrath, B., Gierasch, P., 2006. Cassini CIRS retrievals of ammonia in Jupiter's upper troposphere. Icarus In press.

Bezard, B., Griffith, C., Lacy, J., Owen, T., Dec. 1995. Non-detection of hydrogen cyanide on Jupiter. Icarus 118, 384-391.

Borysow, A., Frommhold, L., Birnbaum, G., 1988. Collision-induced roto-translational absorption spectra of $\mathrm{H}_{2}$-He pairs at temperatures from 40 to $3000 \mathrm{~K}$. Astrophys. J. $326,509-515$.

Borysow, A., Trafton, L., Frommhold, L., Birnbaum, G., 1985. Modelling of pressureinduced far-infrared absorption spectra: Molecular hydrogen pairs. Astrophys. J. 296, $644-654$.

Clarke, J. T., Moos, H. W., Feldman, P. D., Apr. 1982. The far-ultraviolet spectra and geometric albedos of Jupiter and Saturn. Astrophys. J. 255, 806-818.

Festou, M., Atreya, S., Donahue, T., Sandel, B., Shemansky, D., Broadfoot, A., 1981. Composition and thermal profiles of the jovian upper atmosphere determined by the Voyager Ultraviolet Stellar Occultation experiment. J. Geophys. Res. 86 (A7), 57155725 .

Flasar, F., Kunde, V., Abbas, M., Achterberg, R., Ade, P., Barucci, A., Bézard, B., Bjoraker, G., Brasunas, J., Calcutt, S., Carlson, R., Césarsky, C., Conrath, B., Coradini, A., Courtin, R., Coustenis, A., Edberg, S., Edgington, S., Ferrari, C., Fouchet, T., Gautier, D., Gierasch, P., Grossman, K., Irwin, P., Jennings, D., Lellouch, E., Mamoutkine, A., Marten, A., Meyer, J., Nixon, C., Orton, G., Owen, T., Pearl, J., Prangé, R., Raulin, 
F., Read, P., Romani, P., Samuelson, R., Segura, M., Showalter, M., Simon-Miller, A., Smith, M., Spencer, J., L.J., S., Taylor, F., 2004. Exploring the Saturn System in the Thermal Infrared: The Composite Infrared Spectrometer. Space Sci. Rev. 115, 169-297. Fouchet, T., Orton, G., Irwin, P., Calcutt, S., Nixon, C., 2004. Upper limits on hydrogen halides in Jupiter from Cassini/CIRS observations. Icarus 170, 237-241.

Friedson, A., 1999. New observations and modelling of a QBO-like oscillation in Jupiter's stratosphere. Icarus 137, 34-55.

Gladstone, G., Yung, Y., 1983. An Analysis of the Reflection spectrum of Jupiter from $1500 \AA$ to $1740 \AA$. Astrophys. J. 266, 415-424.

Goody, R., West, R., Chen, L., Crisp, D., Dec. 1989. The correlated-k method for radiation calculations in nonhomogeneous atmospheres. Journal of Quantitative Spectroscopy and Radiative Transfer 42, 539-550.

Guerlet, S., Fouchet, T., Bézard, B., Simon-Miller, A. A., Michael Flasar, F., Sep. 2009. Vertical and meridional distribution of ethane, acetylene and propane in Saturn's stratosphere from CIRS/Cassini limb observations. Icarus 203, 214-232.

Halthore, R. N., Allen, Jr., J. E., Decola, P. L., Mar. 1994. A non-LTE model for the Jovian methane infrared emissions at high spectral resolution. Astrophys. J. Lett. 424, L61-L64.

Hanel, R., Conrath, B., Kunde, V., Lowman, P., Maguire, W., Pearl, J., Pirraglia, J., Gautier, D., Gierasch, P., Kumar, S., Nov. 1977. The Voyager infrared spectroscopy and radiometry investigation. Space Sci. Rev. 21, 129-157.

Hesman, B. E., Jennings, D. E., Sada, P. V., Bjoraker, G. L., Achterberg, R. K., SimonMiller, A. A., Anderson, C. M., Boyle, R. J., Nixon, C. A., Fletcher, L. N., McCabe, G. H., Jul. 2009. Saturn's latitudinal $\mathrm{C}_{2} \mathrm{H}_{2}$ and $\mathrm{C}_{2} \mathrm{H}_{6}$ abundance profiles from Cassini/CIRS and ground-based observations. Icarus 202, 249-259.

Howett, C. J. A., Irwin, P. G. J., Teanby, N. A., Simon-Miller, A., Calcutt, S. B., Fletcher, 
L. N., de Kok, R., Oct. 2007. Meridional variations in stratospheric acetylene and ethane in the southern hemisphere of the saturnian atmosphere as determined from Cassini/CIRS measurements. Icarus 190, 556-572.

Irwin, P., Parrish, P., Fouchet, T., Calcutt, S., Taylor, F., Simon-Miller, A., Nixon, C., 2004. Retrievals of jovian upper tropospheric phosphine from Cassini/CIRS. Icarus 172, $37-49$.

Irwin, P., Teanby, N., de Kok, R., Fletcher, L., Howett, C., Tsang, C., Wilson, C., Calcutt, S., Nixon, C., Parrish, P., 2008. The NEMESIS planetary atmosphere radiative transfer and retrieval tool. J. Quant. Spectro. Rad. Trans. 109, 1136-1150.

Jacquinet-Husson, N., Scott, N. A., Chédin, A., Crépeau, L., Armante, R., Capelle, V., Orphal, J., Coustenis, A., Boonne, C., Poulet-Crovisier, N., Barbe, A., Birk, M., Brown, L. R., Camy-Peyret, C., Claveau, C., Chance, K., Christidis, N., Clerbaux, C., Coheur, P. F., Dana, V., Daumont, L., De Backer-Barilly, M. R., Di Lonardo, G., Flaud, J. M., Goldman, A., Hamdouni, A., Hess, M., Hurley, M. D., Jacquemart, D., Kleiner, I., Köpke, P., Mandin, J. Y., Massie, S., Mikhailenko, S., Nemtchinov, V., Nikitin, A., Newnham, D., Perrin, A., Perevalov, V. I., Pinnock, S., Régalia-Jarlot, L., Rinsland, C. P., Rublev, A., Schreier, F., Schult, L., Smith, K. M., Tashkun, S. A., Teffo, J. L., Toth, R. A., Tyuterev, V. G., Vander Auwera, J., Varanasi, P., Wagner, G., Apr. 2008. The GEISA spectroscopic database: Current and future archive for Earth and planetary atmosphere studies. J. Quant. Spectro. Rad. Trans. 109, 1043-1059.

Khare, B. N., Sagan, C., Arakawa, E. T., Suits, F., Callcott, T. A., Williams, M. W., 1984. Optical constants of organic tholins produced in a simulated Titanian atmosphere - From soft X-ray to microwave frequencies. Icarus 60, 127-137.

Lellouch, E., Bézard, B., Moses, J., Davis, G., Drossart, P., Feuchtgruber, H., Bergin, E., Moreno, R., Encrenaz, T., 2002. The origin of water vapour and carbon dioxide in Jupiter's stratosphere. Icarus 159, 112-131. 
Leovy, C., Friedson, A., Orton, G., 1991. The quasiquadrennial oscillation of Jupiter's stratosphere. Nature 354, 380-382.

Livengood, T., Kostiuk, T., Espenak, F., 1993. Temperature and abundances in the Jovian auroral stratosphere 1. Ethane as a probe of the millibar region. J. Geophys. Res. 98, $18813-18822$

Maguire, W., Samuelson, R., Hanel, R., Kunde, V., 1984. Latitudinal variation of acetylene and ethane in the Jovian atmosphere from Voyager IRIS observations. Bull. Amer. Astron. Soc. 16, 541-547, 16th Annual Meeting of the DPS.

Moses, J., Fouchet, T., Yelle, R., Friedson, A., Orton, G., Bézard, B., Drossart, P., Gladstone, G., Kostiuk, T., Livengood, T., 2004. The stratosphere of Jupiter. In: Bagenal, F., Dowling, T., McKinnon, W. (Eds.), Jupiter. Cambridge University Press, Ch. 7, pp. $129-158$.

Niemann, H., Atreya, S., Carignan, G., Donahue, T., Haberman, J., Harpold, D., Hartle, R., Hunten, D., Kasprzak, W., Mahaffy, P., Owen, T., Way, S., 1998. The composition of the Jovian atmosphere as determined by the Galileo probe mass spectrometer. J. Geophys. Res. 103 (E10), 22831-22845.

Nixon, C., Jennings, D., Flaud, J.-M., Bzard, B., Teanby, N., Irwin, P., Ansty, T., Coustenis, A., Flasar, F., 2009a. Titan's prolific propane: the Cassini CIRS perspective. Plan. and Space Sci. 57, 1573-1585.

Nixon, C., Teanby, N., Calcutt, S., Aslam, S., Jennings, D., Kunde, V., Flasar, F., Irwin, P., Taylor, F., 2009b. Infrared limb sounding of Titan with Cassini CIRS: effects of the detector spatial responses. Appl. Opt. 48 (10), 1912-1925.

Nixon, C. A., Achterberg, R. K., Conrath, B. J., Irwin, P. G. J., Teanby, N. A., Fouchet, T., Parrish, P. D., Romani, P. N., Abbas, M., Leclair, A., Strobel, D., Simon-Miller, A. A., Jennings, D. J., Flasar, F. M., Kunde, V. G., May 2007. Meridional variations of $\mathrm{C}_{2} \mathrm{H}_{2}$ and $\mathrm{C}_{2} \mathrm{H}_{6}$ in Jupiter's atmosphere from Cassini CIRS infrared spectra. Icarus 
188, 47-71.

Noll, K. S., Knacke, R. F., Tokunaga, A. T., Lacy, J. H., Beck, S., Serabyn, E., Mar. 1986. The abundances of ethane and acetylene in the atmospheres of Jupiter and Saturn. Icarus 65, 257-263.

Owen, T., Caldwell, J., Rivolo, A. R., Moore, V., Lane, A. L., Sagan, C., Hunt, G. E., Ponnamperuma, C., Feb. 1980. Observations of the spectrum of Jupiter from 1500 to $2000 \AA$ with the IUE. Astrophys. J. Lett. 236, L39-L42.

Press, W., Teukolsky, S., Vetterling, W., Flannery, B., 1992. Numerical Recipes in C, Second Edition. Cam. Univ. Press, Cambridge, U.K.

Rodgers, C., 2000. Inverse Methods for Atmospheric Sounding. Series on Atmospheric, Oceanic and Planetary Physics - Vol. 2. World Scientific, Singapore.

Rothman, L. S., Gordon, I. E., Barbe, A., Benner, D. C., Bernath, P. F., Birk, M., Boudon, V., Brown, L. R., Campargue, A., Champion, J., Chance, K., Coudert, L. H., Dana, V., Devi, V. M., Fally, S., Flaud, J., Gamache, R. R., Goldman, A., Jacquemart, D., Kleiner, I., Lacome, N., Lafferty, W. J., Mandin, J., Massie, S. T., Mikhailenko, S. N., Miller, C. E., Moazzen-Ahmadi, N., Naumenko, O. V., Nikitin, A. V., Orphal, J., Perevalov, V. I., Perrin, A., Predoi-Cross, A., Rinsland, C. P., Rotger, M., Šimečková, M., Smith, M. A. H., Sung, K., Tashkun, S. A., Tennyson, J., Toth, R. A., Vandaele, A. C., Vander Auwera, J., Jun. 2009. The HITRAN 2008 molecular spectroscopic database. Journal of Quantitative Spectroscopy and Radiative Transfer 110, 533-572.

Seiff, A., Kirk, D., Knight, T., Young, R., Mihalov, J., Young, L., Milos, F., Schubert, G., Blanchard, R., Atkinson, D., 1998. Thermal structure of Jupiter's atmosphere near the edge of a 5- $\mu \mathrm{m}$ hot spot in the north equatorial belt. J. Geophys. Res. 103, 22857-22889. Simon-Miller, A., Conrath, B., Gierasch, P., Orton, G., Achterberg, R., Fisher, B., Flasar, F., 2006. Jupiter's atmospheric temperatures: from Voyager IRIS to Cassini CIRS. Icarus 180, 98-112. 
${ }_{563}$ Vander Auwera, J., Moazzen-Ahmadi, N., Flaud, J.-M., 2007. Towards an accurate database for the $12 \mu \mathrm{m}$ region of the ethane spectrum. Astrophys. J. 662, 750-757. von Zahn, U., Hunten, D., Lehmacher, G., 1998. Helium in Jupiter's atmosphere: results from the Galileo probe helium interferometer experiment. J. Geophys. Res. 103 (E10), $22815-22829$

Wagener, R., Caldwell, J., Owen, T., Kim, S.-J., Encrenaz, T., Combes, M., 1985. The Jovian stratosphere in the ultraviolet. Icarus 63, 222-236.

Yelle, R., Griffith, C., Young, L., 2001. Structure of the Jovian stratosphere at the Galileo probe entry site. Icarus 152, 331-346. 
TABLE I

Cassini CIRS Observational Data

\begin{tabular}{|c|c|c|c|c|c|}
\hline $\begin{array}{c}\text { Mean } \\
\text { Latitude }\end{array}$ & $\begin{array}{c}\text { No. of FP3 } \\
\text { Spectra }\end{array}$ & $\begin{array}{c}\text { No. of FP4 } \\
\text { Spectra }\end{array}$ & $\begin{array}{c}\text { Mean Emis. } \\
\text { Angle }\left(^{\circ}\right)\end{array}$ & $\begin{array}{c}\text { NESR } \\
760 \mathrm{~cm}^{-1}\end{array}$ & $\begin{array}{c}\text { NESR } \\
1300 \mathrm{~cm}^{-1}\end{array}$ \\
\hline-66.30 & 19 & 7 & 71.21 & $3.50 \times 10^{-9}$ & $8.50 \times 10^{-10}$ \\
\hline-62.24 & 73 & 67 & 67.76 & $1.92 \times 10^{-9}$ & $3.30 \times 10^{-10}$ \\
\hline-57.28 & 172 & 139 & 64.13 & $1.50 \times 10^{-9}$ & $2.30 \times 10^{-10}$ \\
\hline-52.49 & 231 & 234 & 60.81 & $1.36 \times 10^{-9}$ & $1.89 \times 10^{-10}$ \\
\hline-47.54 & 306 & 313 & 56.93 & $1.09 \times 10^{-9}$ & $1.71 \times 10^{-10}$ \\
\hline-42.31 & 559 & 332 & 52.92 & $0.94 \times 10^{-9}$ & $1.71 \times 10^{-10}$ \\
\hline-37.36 & 855 & 366 & 48.96 & $0.94 \times 10^{-9}$ & $1.74 \times 10^{-10}$ \\
\hline-32.48 & 1171 & 402 & 45.76 & $1.14 \times 10^{-9}$ & $1.71 \times 10^{-10}$ \\
\hline-27.84 & 644 & 377 & 38.73 & $1.07 \times 10^{-9}$ & $1.71 \times 10^{-10}$ \\
\hline-22.32 & 446 & 523 & 36.29 & $1.07 \times 10^{-9}$ & $1.93 \times 10^{-10}$ \\
\hline-17.37 & 427 & 501 & 32.23 & $1.02 \times 10^{-9}$ & $1.65 \times 10^{-10}$ \\
\hline-12.20 & 471 & 2144 & 34.77 & $1.01 \times 10^{-9}$ & $1.16 \times 10^{-10}$ \\
\hline-7.93 & 437 & 1149 & 27.51 & $1.07 \times 10^{-9}$ & $1.59 \times 10^{-10}$ \\
\hline-2.65 & 442 & 503 & 23.41 & $1.07 \times 10^{-9}$ & $2.07 \times 10^{-10}$ \\
\hline 2.50 & 505 & 551 & 21.89 & $1.01 \times 10^{-9}$ & $1.83 \times 10^{-10}$ \\
\hline 7.55 & 413 & 536 & 22.49 & $1.08 \times 10^{-9}$ & $1.88 \times 10^{-10}$ \\
\hline 12.56 & 580 & 558 & 26.31 & $1.07 \times 10^{-9}$ & $2.02 \times 10^{-10}$ \\
\hline 17.52 & 604 & 568 & 28.16 & $1.03 \times 10^{-9}$ & $2.05 \times 10^{-10}$ \\
\hline 22.44 & 525 & 492 & 29.66 & $1.09 \times 10^{-9}$ & $2.20 \times 10^{-10}$ \\
\hline 27.33 & 478 & 568 & 34.89 & $1.08 \times 10^{-9}$ & $2.52 \times 10^{-10}$ \\
\hline 32.47 & 464 & 548 & 38.67 & $1.09 \times 10^{-9}$ & $2.39 \times 10^{-10}$ \\
\hline 37.51 & 491 & 558 & 41.09 & $1.17 \times 10^{-9}$ & $2.11 \times 10^{-10}$ \\
\hline 42.56 & 430 & 489 & 46.05 & $1.14 \times 10^{-9}$ & $2.13 \times 10^{-10}$ \\
\hline 47.37 & 437 & 400 & 50.57 & $1.16 \times 10^{-9}$ & $2.22 \times 10^{-10}$ \\
\hline 52.29 & 381 & 402 & 55.60 & $1.15 \times 10^{-9}$ & $2.30 \times 10^{-10}$ \\
\hline 57.16 & 334 & 294 & 59.12 & $1.23 \times 10^{-9}$ & $2.51 \times 10^{-10}$ \\
\hline 62.24 & 220 & 187 & 63.54 & $1.43 \times 10^{-9}$ & $3.10 \times 10^{-10}$ \\
\hline 67.14 & 96 & 97 & 66.42 & $1.94 \times 10^{-9}$ & $3.79 \times 10^{-10}$ \\
\hline
\end{tabular}

N. B. this table, included here for completeness, is identical to TABLE I of Nixon et al. (2007). 
TABLE II

Voyager IRIS Observational Data

\begin{tabular}{|c|c|c|c|}
\hline Mean Latitude & No. of spectra & Mean Emission Angle & $\mathrm{NESR}^{\dagger}$ \\
\hline-59.97 & 27 & 60.39 & $9.62 \times 10^{-10}$ \\
\hline-55.02 & 32 & 54.65 & $8.84 \times 10^{-10}$ \\
\hline-49.49 & 43 & 49.76 & $7.62 \times 10^{-10}$ \\
\hline-45.04 & 55 & 45.34 & $6.74 \times 10^{-10}$ \\
\hline-40.73 & 46 & 40.43 & $7.37 \times 10^{-10}$ \\
\hline-34.29 & 52 & 34.06 & $6.93 \times 10^{-10}$ \\
\hline-30.34 & 62 & 30.49 & $6.35 \times 10^{-10}$ \\
\hline-25.01 & 53 & 25.33 & $6.87 \times 10^{-10}$ \\
\hline-19.49 & 63 & 20.91 & $6.30 \times 10^{-10}$ \\
\hline-15.00 & 68 & 19.52 & $6.06 \times 10^{-10}$ \\
\hline-9.59 & 74 & 17.16 & $5.81 \times 10^{-10}$ \\
\hline-4.80 & 88 & 15.22 & $5.33 \times 10^{-10}$ \\
\hline-0.34 & 79 & 12.62 & $5.63 \times 10^{-10}$ \\
\hline 4.79 & 73 & 10.32 & $5.85 \times 10^{-10}$ \\
\hline 9.72 & 76 & 10.56 & $5.74 \times 10^{-10}$ \\
\hline 14.82 & 65 & 12.01 & $6.20 \times 10^{-10}$ \\
\hline 20.02 & 55 & 16.67 & $6.74 \times 10^{-10}$ \\
\hline 25.19 & 58 & 21.55 & $6.57 \times 10^{-10}$ \\
\hline 30.01 & 60 & 26.04 & $6.45 \times 10^{-10}$ \\
\hline 35.05 & 58 & 30.50 & $6.57 \times 10^{-10}$ \\
\hline 39.91 & 59 & 35.87 & $6.51 \times 10^{-10}$ \\
\hline 44.04 & 48 & 40.10 & $7.22 \times 10^{-10}$ \\
\hline 50.05 & 40 & 45.35 & $7.91 \times 10^{-10}$ \\
\hline 54.35 & 37 & 49.86 & $8.22 \times 10^{-10}$ \\
\hline 58.63 & 22 & 54.34 & $1.07 \times 10^{-09}$ \\
\hline
\end{tabular}


TABLE III

Comparison of Altitude Sensitivity: Equator

\begin{tabular}{|c|c|c|c|c|c|}
\hline $\begin{array}{l}\text { Wavenumber } \\
\mathrm{cm}^{-1}\end{array}$ & $\begin{array}{l}\text { Primary } \\
\text { Opacity }\end{array}$ & $\begin{array}{l}\text { Retrieved } \\
\text { Parameter }\end{array}$ & $\begin{array}{c}\text { Troposphere } \\
\text { Range (mbar) }\end{array}$ & $\begin{array}{c}\text { Lower } \\
\text { Stratosphere } \\
\text { Range (mbar) } \\
\end{array}$ & $\begin{array}{c}\text { Upper } \\
\text { Stratosphere } \\
\text { Range (mbar) }\end{array}$ \\
\hline 625 & $\mathrm{H}_{2}$ & Temp & $\begin{array}{c}98-339(206) \\
\mathbf{1 0 6}-\mathbf{3 3 9}(\mathbf{2 0 6})\end{array}$ & & \\
\hline 722 & $\mathrm{C}_{2} \mathrm{H}_{2}$ & VMR & $\begin{array}{c}74-339(178) \\
\mathbf{2 6 6}-\mathbf{7 4 8}(\mathbf{5 1 6})\end{array}$ & $\begin{aligned} 0.93-31.27 & (9.80) \\
\mathbf{0 . 1 2}-\mathbf{7 . 2 1} & (\mathbf{3 . 7 9})\end{aligned}$ & \\
\hline 729 & $\mathrm{C}_{2} \mathrm{H}_{2}$ & VMR & $\begin{array}{c}84-374(219) \\
\mathbf{2 6 2 - 7 7 2}(\mathbf{5 2 5})\end{array}$ & $\begin{aligned} 0.03-28.39 & (4.59) \\
\mathbf{0 . 1 7}-\mathbf{7 . 4 5} & (\mathbf{3 . 7 9})\end{aligned}$ & \\
\hline 731 & $\mathrm{C}_{2} \mathrm{H}_{2}$ & VMR & $\begin{array}{c}\text { 87-392 (242) } \\
\mathbf{2 6 2 - 7 7 2}(\mathbf{5 3 3 )}\end{array}$ & $\begin{array}{r}0.01-2.83(0.15) \\
\mathbf{0 . 1 7}-\mathbf{7 . 4 5}(\mathbf{3 . 8 5})\end{array}$ & \\
\hline 822 & $\mathrm{C}_{2} \mathrm{H}_{6}$ & VMR & $\begin{array}{l}137-597(356) \\
\mathbf{7 3 - 6 7 9}(\mathbf{4 3 2})\end{array}$ & $\begin{aligned} 0.70-13.97 & (4.38) \\
\mathbf{0 . 8 6}-\mathbf{1 0 . 4 5} & (\mathbf{4 . 3 8})\end{aligned}$ & \\
\hline 1250 & $\mathrm{CH}_{4}$ & Temp & & $\begin{array}{r}1.59-21.59(5.95) \\
\mathbf{2 . 3 7 - 1 5 . 3 9}(\mathbf{6 . 1 4})\end{array}$ & \\
\hline 1304 & $\mathrm{CH}_{4}$ & Temp & & $\begin{array}{r}0.92-7.21 \\
(3.27) \\
\mathbf{1 . 0 1}-\mathbf{7 . 6 9}(\mathbf{3 . 6 1})\end{array}$ & \\
\hline 1306 & $\mathrm{CH}_{4}$ & Temp & & $\begin{array}{r}0.40-2.79 \\
(1.25) \\
\mathbf{0 . 7 6}-\mathbf{9 . 9 6}(\mathbf{3 . 1 2})\end{array}$ & $\begin{aligned} 0.003-0.025 & (0.006) \\
\mathbf{0 . 0 0 3 - 0 . 0 1 9} & (\mathbf{0 . 0 0 7})\end{aligned}$ \\
\hline
\end{tabular}

$\mathrm{VMR}=$ Volume Mixing Ratio.

Italic text is Cassini CIRS; bold text is Voyager IRIS.

In each case the range and peak (in parentheses) of the sensitivity is given. 
TABLE IV

Comparison of Altitude Sensitivity: North

\begin{tabular}{|c|c|c|c|c|c|}
\hline $\begin{array}{l}\text { Wavenumber } \\
\mathrm{cm}^{-1}\end{array}$ & $\begin{array}{l}\text { Primary } \\
\text { Opacity }\end{array}$ & $\begin{array}{l}\text { Retrieved } \\
\text { Parameter }\end{array}$ & $\begin{array}{c}\text { Troposphere } \\
\text { Range (mbar) }\end{array}$ & $\begin{array}{c}\text { Lower } \\
\text { Stratosphere } \\
\text { Range (mbar) }\end{array}$ & $\begin{array}{c}\text { Upper } \\
\text { Stratosphere } \\
\text { Range (mbar) }\end{array}$ \\
\hline 625 & $\mathrm{H}_{2}$ & Temp & $\begin{aligned} 63-254 & (159) \\
\mathbf{6 6}-\mathbf{2 6 2} & (\mathbf{1 5 6})\end{aligned}$ & & \\
\hline 722 & $\mathrm{C}_{2} \mathrm{H}_{2}$ & VMR & $\begin{array}{c}71-284(106) \\
\mathbf{2 0 6}-\mathbf{5 8 7}(\mathbf{3 9 9})\end{array}$ & $\begin{array}{r}3.22-39.19(16.95) \\
\mathbf{1 . 5 1 - 1 1 . 1 5}(\mathbf{5 . 3 1 )}\end{array}$ & \\
\hline 729 & $\mathrm{C}_{2} \mathrm{H}_{2}$ & VMR & $\begin{array}{c}74-323(111) \\
\mathbf{2 0 2 - 5 9 7}(\mathbf{3 9 9})\end{array}$ & $\begin{array}{c}0.09-39.19(17.23) \\
\mathbf{1 . 5 4 - 1 1 . 8 9}(\mathbf{5 . 4 8})\end{array}$ & \\
\hline 731 & $\mathrm{C}_{2} \mathrm{H}_{2}$ & VMR & $\begin{array}{c}\text { 73-392 (242) } \\
\mathbf{2 0 2 - 5 9 7}(\mathbf{3 9 9})\end{array}$ & $\begin{array}{c}0.06-2.83(0.16) \\
\mathbf{1 . 5 4 - 1 2 . 0 8}(\mathbf{5 . 5 7})\end{array}$ & \\
\hline 822 & $\mathrm{C}_{2} \mathrm{H}_{6}$ & VMR & $\begin{array}{c}90-525(318) \\
\mathbf{1 3 5}-\mathbf{5 5 1}(\mathbf{3 4 5 )}\end{array}$ & $\begin{aligned} 1.09-19.91 & (2.83) \\
\mathbf{2 . 7 0}-\mathbf{2 1 . 5 9} & (\mathbf{9 . 0 4})\end{aligned}$ & \\
\hline 1250 & $\mathrm{CH}_{4}$ & Temp & & $\begin{array}{r}2.09-25.77(9.64) \\
\mathbf{2 . 3 7 - 2 1 . 5 9}(\mathbf{7 . 9 5})\end{array}$ & \\
\hline 1304 & $\mathrm{CH}_{4}$ & Temp & & $\begin{array}{r}1.19-6.44(2.97) \\
\mathbf{0 . 7 7}-\mathbf{6 . 9 9}(\mathbf{2 . 8 8})\end{array}$ & \\
\hline 1306 & $\mathrm{CH}_{4}$ & Temp & & $\begin{array}{c}0.39-2.45(1.31) \\
\mathbf{0 . 5 9 - 1 4 . 4 3}(\mathbf{2 . 3 0})\end{array}$ & $\begin{array}{r}0.002-0.007(0.004) \\
\mathbf{0 . 0 0 3 - 0 . 0 1 5}(\mathbf{0 . 0 0 5})\end{array}$ \\
\hline
\end{tabular}

VMR = Volume Mixing Ratio.

Italic text is Cassini CIRS; bold text is Voyager IRIS.

In each case the range and peak (in parentheses) of the sensitivity is given. 


\section{TABLE V}

\section{Comparison to Previous Results}

\begin{tabular}{|c|c|c|c|c|c|c|c|}
\hline $\begin{array}{r}\text { Gas } \\
\text { Species }\end{array}$ & Ref. & $\begin{array}{l}\text { Press. } \\
\text { (mbar) }\end{array}$ & Lat. $^{\dagger}$ & Date & $\begin{array}{l}\text { Mole } \\
\text { Frac. }\end{array}$ & $\begin{array}{l}\text { Voyager } 79 \\
\text { Mole Frac. }\end{array}$ & $\begin{array}{c}\text { Cassini } 2000 \\
\text { Mole Frac. }\end{array}$ \\
\hline \multirow[t]{5}{*}{$\mathrm{C}_{2} \mathrm{H}_{6}$} & F81 & 0.005 & $16.5^{\circ} \mathrm{N}$ & $07 / 79$ & $(2.5 \pm 1.7) \mathrm{ppm}$ & $\mathrm{N} / \mathrm{A}$ & - \\
\hline & G83 & 4 & $30^{\circ} \mathrm{S}-30^{\circ} \mathrm{N}$ & $12 / 78$ & $(6.6 \pm 5.3) \mathrm{ppm}$ & $(2.3 \pm 0.7) \mathrm{ppm}$ & - \\
\hline & & & & $\& 6 / 79$ & & & \\
\hline & N86 & 5 & $8^{\circ} \mathrm{S}-8^{\circ} \mathrm{N}$ & $06 / 80$ & $(2.6 \pm 0.9) \mathrm{ppm}$ & $(1.9 \pm 0.6) \mathrm{ppm}$ & 一 \\
\hline & L93 & $0.3-3$ & $45-55^{\circ} \mathrm{N}$ & $12 / 89$ & $(3.6 \pm 0.9) \mathrm{ppm}$ & - & $(9.4 \pm 1.8) \mathrm{ppm}^{\ddagger}$ \\
\hline \multirow[t]{10}{*}{$\mathrm{C}_{2} \mathrm{H}_{2}$} & $\mathrm{O} 80$ & 10 & $30^{\circ} \mathrm{S}-30^{\circ} \mathrm{N}$ & $1 / 79$ & $19 \mathrm{ppb}$ & $(13 \pm 5) \mathrm{ppb}$ & - \\
\hline & & & & $\& 4 / 79$ & & & \\
\hline & $\mathrm{C} 82$ & 10 & $30^{\circ} \mathrm{S}-30^{\circ} \mathrm{N}$ & $1978-1980$ & $(100 \pm 50) \mathrm{ppb}$ & $(13 \pm 5) \mathrm{ppb}$ & - \\
\hline & G83 & 10 & $30^{\circ} \mathrm{S}-30^{\circ} \mathrm{N}$ & $12 / 78$ & $(100 \pm 10) \mathrm{ppb}$ & $(13 \pm 5) \mathrm{ppb}$ & 一 \\
\hline & & & & $\& 6 / 79$ & & & \\
\hline & W85 & 30 & $30^{\circ} \mathrm{S}-30^{\circ} \mathrm{N}$ & 1978-1980 & $(30 \pm 10) \mathrm{ppb}$ & $\mathrm{N} / \mathrm{A}$ & - \\
\hline & N86 & 3 & $8^{\circ} \mathrm{S}-8^{\circ} \mathrm{N}$ & $6 / 80$ & $(34 \pm 17) \mathrm{ppb}$ & $(62 \pm 20) \mathrm{ppb}$ & - \\
\hline & B95 & 0.1 & $10-36^{\circ} \mathrm{S}$ & $1 / 91$ & $4 \mathrm{ppm}$ & $\mathrm{N} / \mathrm{A}$ & - \\
\hline & B95 & 1 & $10-36^{\circ} \mathrm{S}$ & $1 / 91$ & $100 \mathrm{ppb}$ & $(250 \pm 100) \mathrm{ppb}$ & - \\
\hline & B95 & 10 & $10-36^{\circ} \mathrm{S}$ & $1 / 91$ & $1 \mathrm{ppb}$ & $(16 \pm 6) \mathrm{ppb}$ & - \\
\hline
\end{tabular}

${ }^{\dagger}$ Voyager/Cassini data calculated at mean latitude of range, where applicable. ${ }^{\ddagger}$ At 3 mbar. References: O80 = Owen et al. (1980); F81 = Festou et al. (1981); C82=

Clarke et al. (1982); G83 = Gladstone and Yung (1983); W85 = Wagener et al. (1985);

N86 = Noll et al. (1986); L93 = Livengood et al. (1993); B95 = Bezard et al. (1995). 


\section{Figure Captions}

Fig. 11 Initial assumed a priori temperature (left) and gas profiles (right) for Jupiter atmospheric model.

Fig. 2] Functional derivatives for temperature from the Voyager IRIS spectral data: (a) from the $\mathrm{H}_{2}$ continuum region giving tropospheric information, and (b) from the $\mathrm{CH}_{4} \nu_{4}$ band, sensitive to the lower stratosphere near 5 mbar and the upper stratosphere at 5 $\mu$ bar.

Fig. 3 Functional derivative for gas abundance from the $\mathrm{C}_{2} \mathrm{H}_{2} \nu_{5}$ band. Note the emission emanating from the stratosphere at 1 mbar, and also tropospheric absorption at 200 mbar. Some information is available from the upper stratosphere at 10-100 $\mu$ bar due to the Q-branch $\left(730 \mathrm{~cm}^{-1}\right)$.

Fig. 4 Functional derivative for gas abundance from the $\mathrm{C}_{2} \mathrm{H}_{6} \quad \nu_{9}$ band. Note the emission emanating from the stratosphere at 5 mbar, and also tropospheric absorption at $\sim 200$ mbar.

Fig. 5 Examples of the FWHM sensitivity (symbols at bar ends) and peak sensitivity for the contribution functions at various representative wavenumbers, comparing Cassini $(\times)$ to Voyager $(\diamond)$, computed for Jupiter's equator. Even though the spectral resolutions are quite different $\left(0.5 \mathrm{~cm}^{-1}\right.$ versus $\left.4.3 \mathrm{~cm}^{-1}\right)$, the vertical information regions are similar except for the $\mathrm{C}_{2} \mathrm{H}_{2}$ hotband near $731 \mathrm{~cm}^{-1}$ for which the peak has moved considerably lower for IRIS due to lower spectral resolution.

Fig. 6] As in previous figure, but computed for $58^{\circ} \mathrm{N}$.

Fig. 7 Comparison of the vertically-varying collisional relaxation time $\left(\tau_{\mathrm{C}}\right)$ for the $\nu_{4}$ band of $\mathrm{CH}_{4}$ to the spontaneous emission timescale $\tau_{\mathrm{A}}$, assumed $0.4 \mathrm{~s}$ following Halthore et al. (1994). The break-down of LTE conditions is computed to be at $\sim 0.8 \mu$ bar. 
Fig. 8 Retrieved temperatures from Voyager IRIS data (a) and Cassini CIRS (b). (c) shows the difference: Cassini-Voyager. This may be compared to Simon-Miller et al. (2006) Fig. 2. We find that the stratosphere at $\sim 2$ mbar is warmer in the north in 2000 compared to 1979 , and at 0.01 mbar is cooler.

Fig. 9. Comparison of retrieved abundances for $\mathrm{C}_{2} \mathrm{H}_{2}$ at the (a) Voyager and (b) Cassini epochs. The vertical range has been restricted to match the smaller span (IRIS) (see Figs. [5 and 6). Abundances in the lower stratosphere ( 10 mbar) have dropped substantially in 2000 at the poles relative to 1979.

Fig. 10 Comparison of retrieved abundances for $\mathrm{C}_{2} \mathrm{H}_{6}$ at the (a) Voyager and (b) Cassini epochs. The changes seen are much less dramatic than for $\mathrm{C}_{2} \mathrm{H}_{2}$, nevertheless the Cassini (2000) stratospheric abundances appear to be higher and more symmetric in latitude compared to the Voyager (1979) contours, which show a positive bias to southern hemisphere.

Fig. 11 Comparison of the retrieved abundances of $\mathrm{C}_{2} \mathrm{H}_{2}$ and $\mathrm{C}_{2} \mathrm{H}_{6}$ from the Cassini CIRS dataset, taking the difference between the 2007 and 2010 retrievals. The differences for acetylene, due mainly to changes in the instrumental lineshape assumed (see text for discussion), are typically 1-10\% across most of the range (c.f. formal retrieval errors of $\sim 40--50 \%$ ), reaching maximum divergences of $+20 \%$ and $-40 \%$ in the northern stratosphere and troposphere respectively, which approach the size of the inferred random errors. For ethane, the differences are greater, with large changes (-40 to -60\%) occuring in the mid-stratosphere at 10 mbar at the peak of the contribution function, and are significantly larger than the random errors (15-20\%). This is due to the revised $\nu_{9}$ band intensities used for $\mathrm{C}_{2} \mathrm{H}_{6}$, as discussed in $§ 3.2$.

Fig. 12 Photochemical production (solid color lines) and loss (broken color lines) times (time for mixing ratio of species to increased/decreased by a factor of two) for $\mathrm{C}_{2} \mathrm{H}_{2}$ (red) 
621 and $\mathrm{C}_{2} \mathrm{H}_{6}$ (blue) for the model used in Nixon et al. (2007). These are compared to the ${ }_{622}$ eddy mixing time, the Jovian year, and half the period of the solar cycle. 

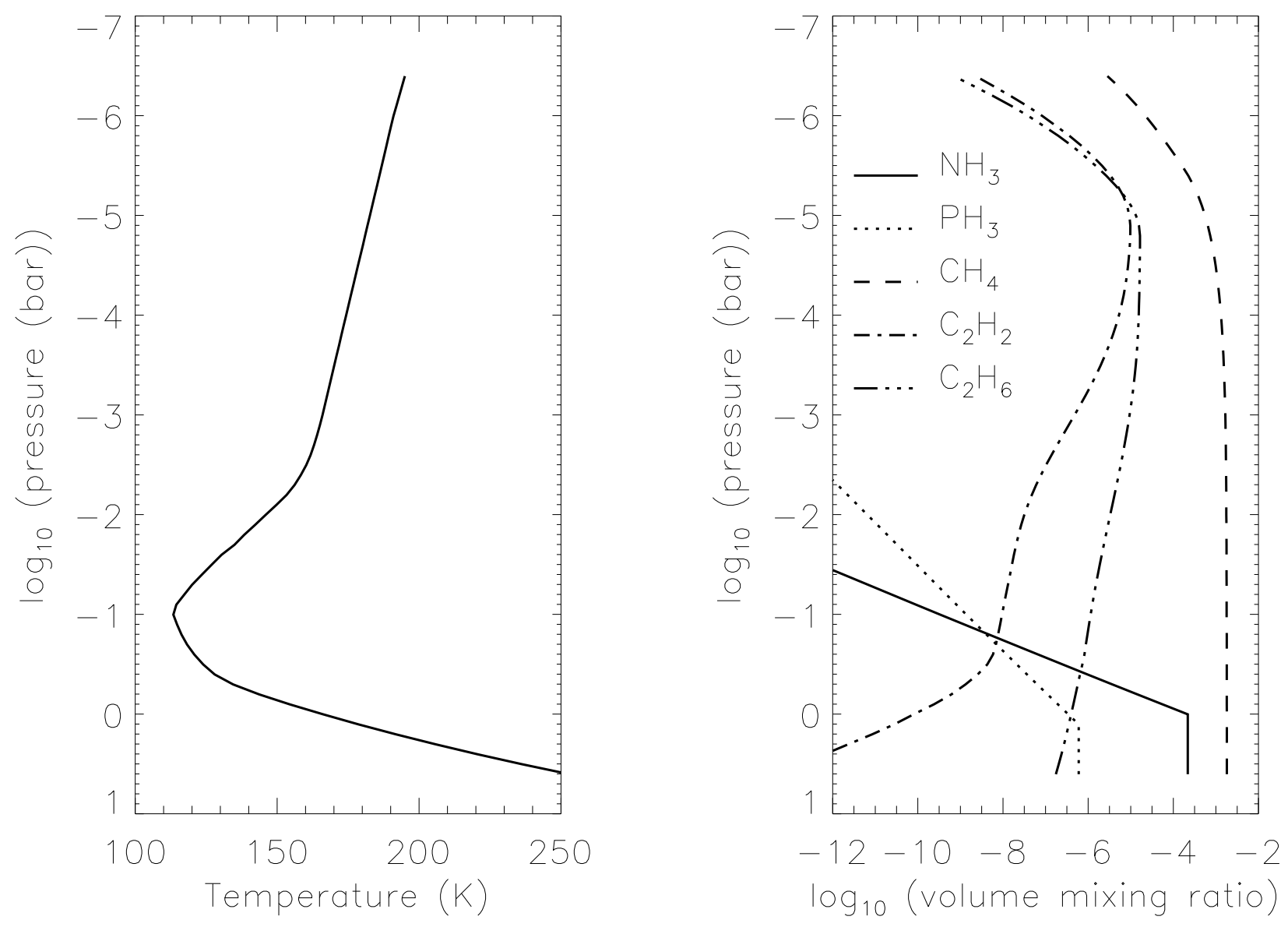

${ }_{623}$ Nixon et al. Figure 1 
(a) $\mathrm{H}_{2}$ continuum functional derivative

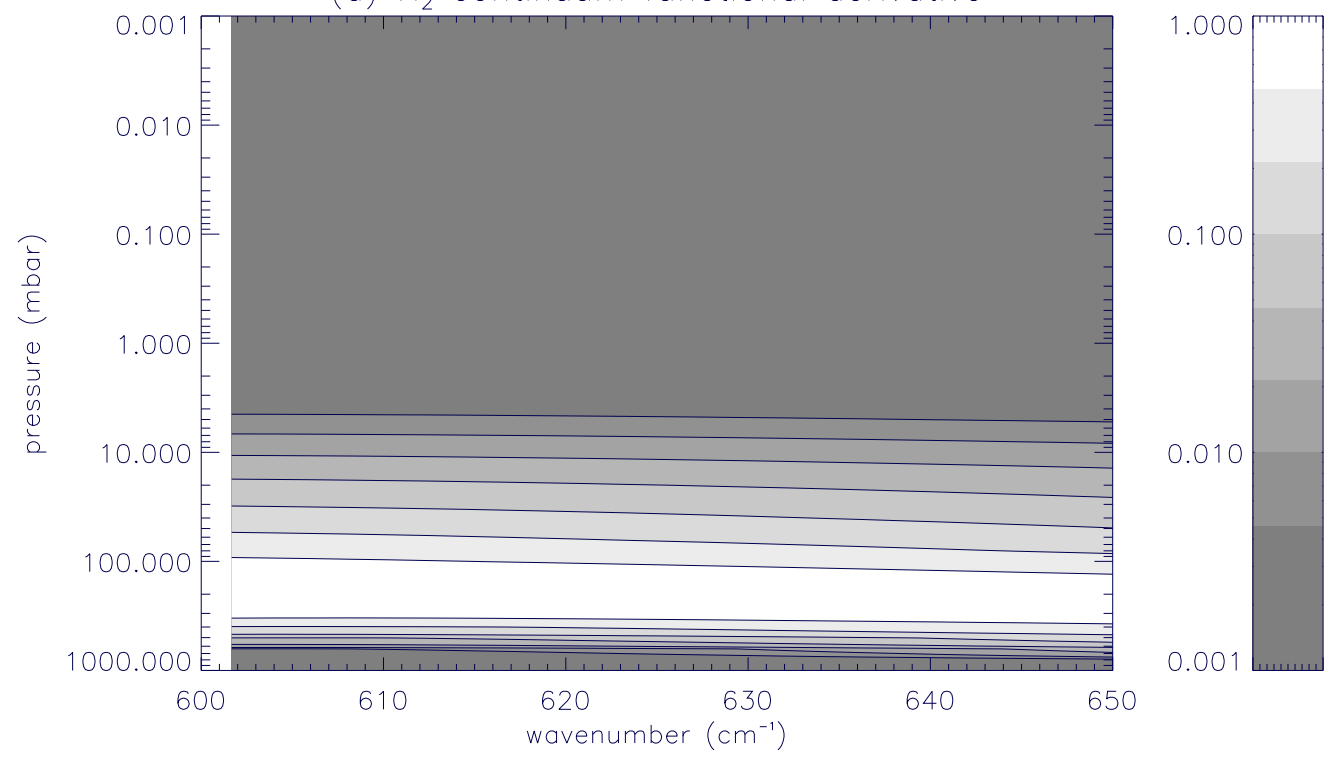

(b) $\mathrm{CH}_{4} \nu_{4}$ band functional derivative

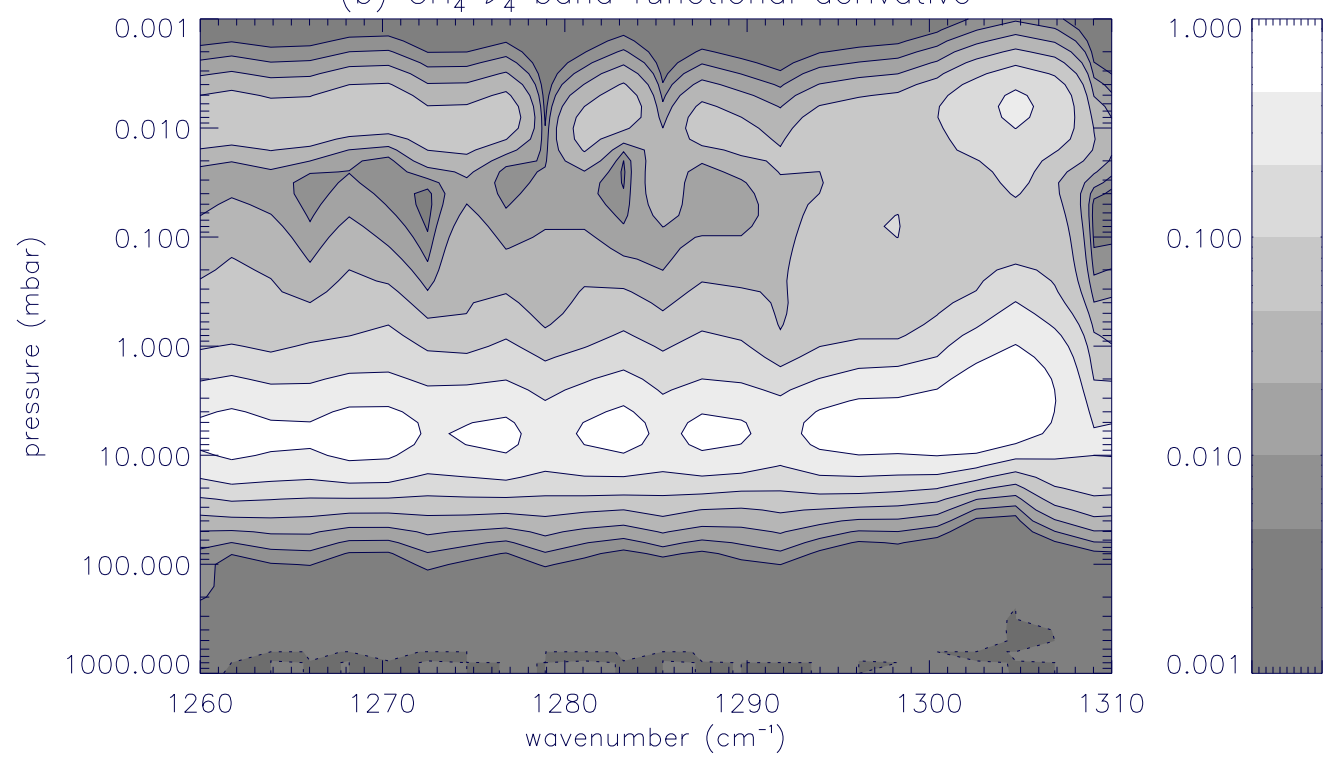

Nixon et al. Figure 2 


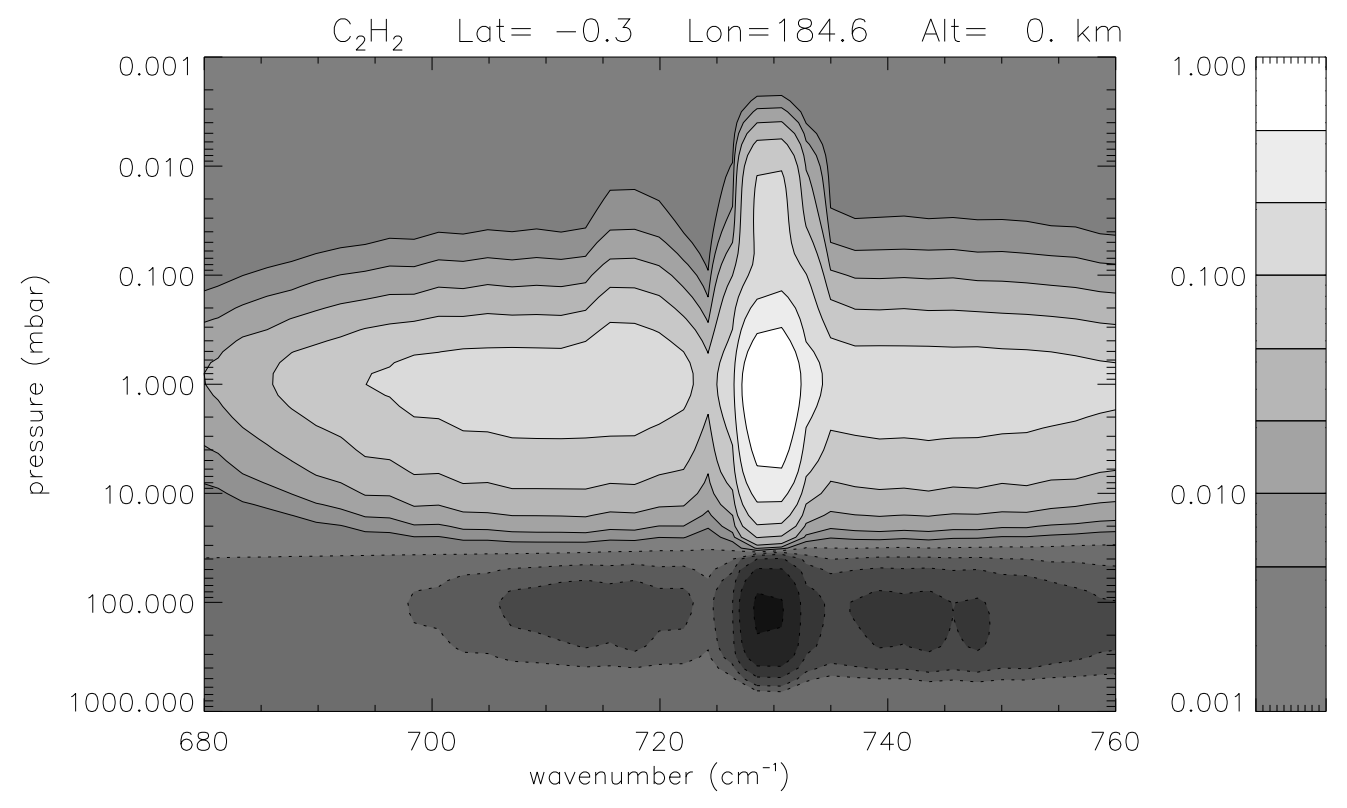




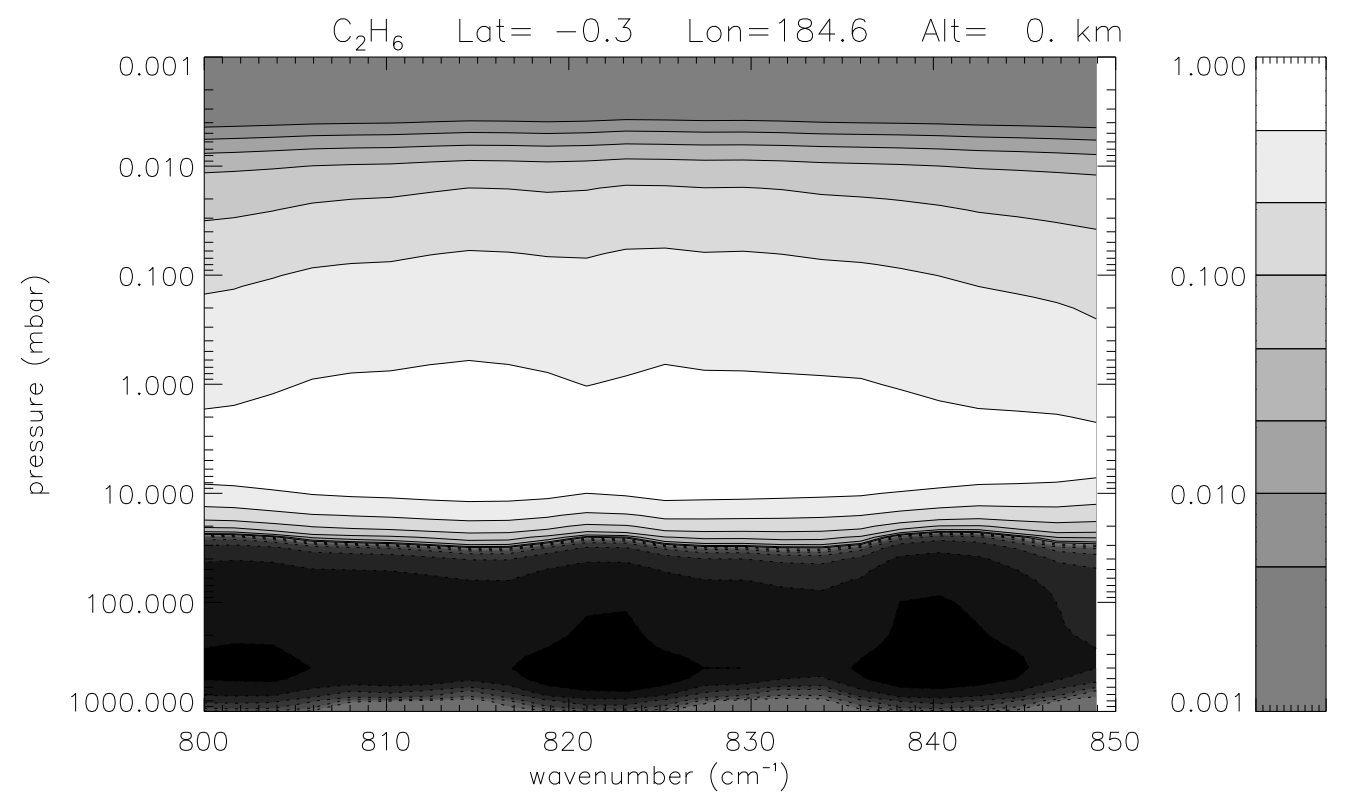

${ }_{626}$ Nixon et al. Figure 4 


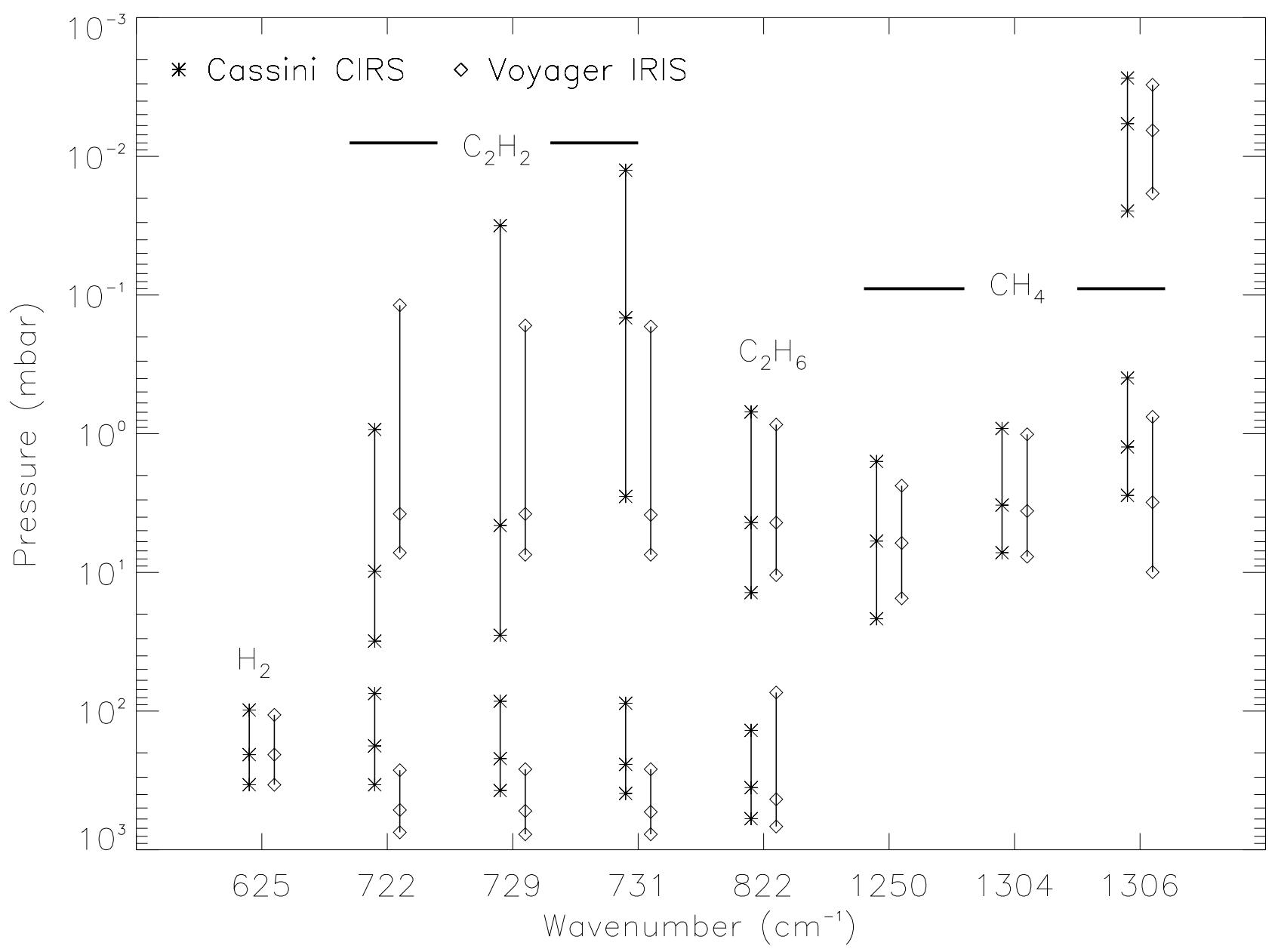

627

Nixon et al. Figure 5 


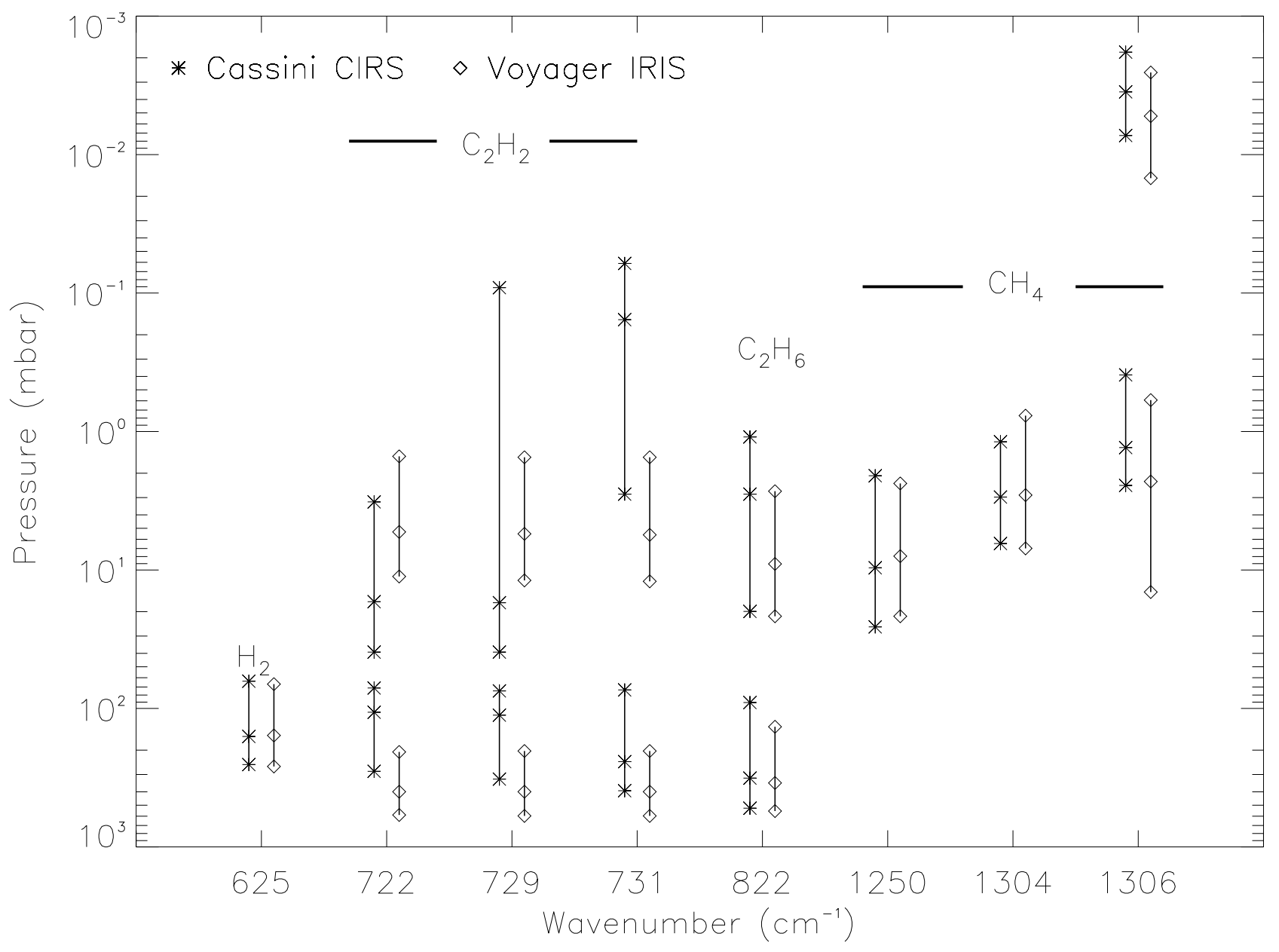

628

Nixon et al. Figure 6 


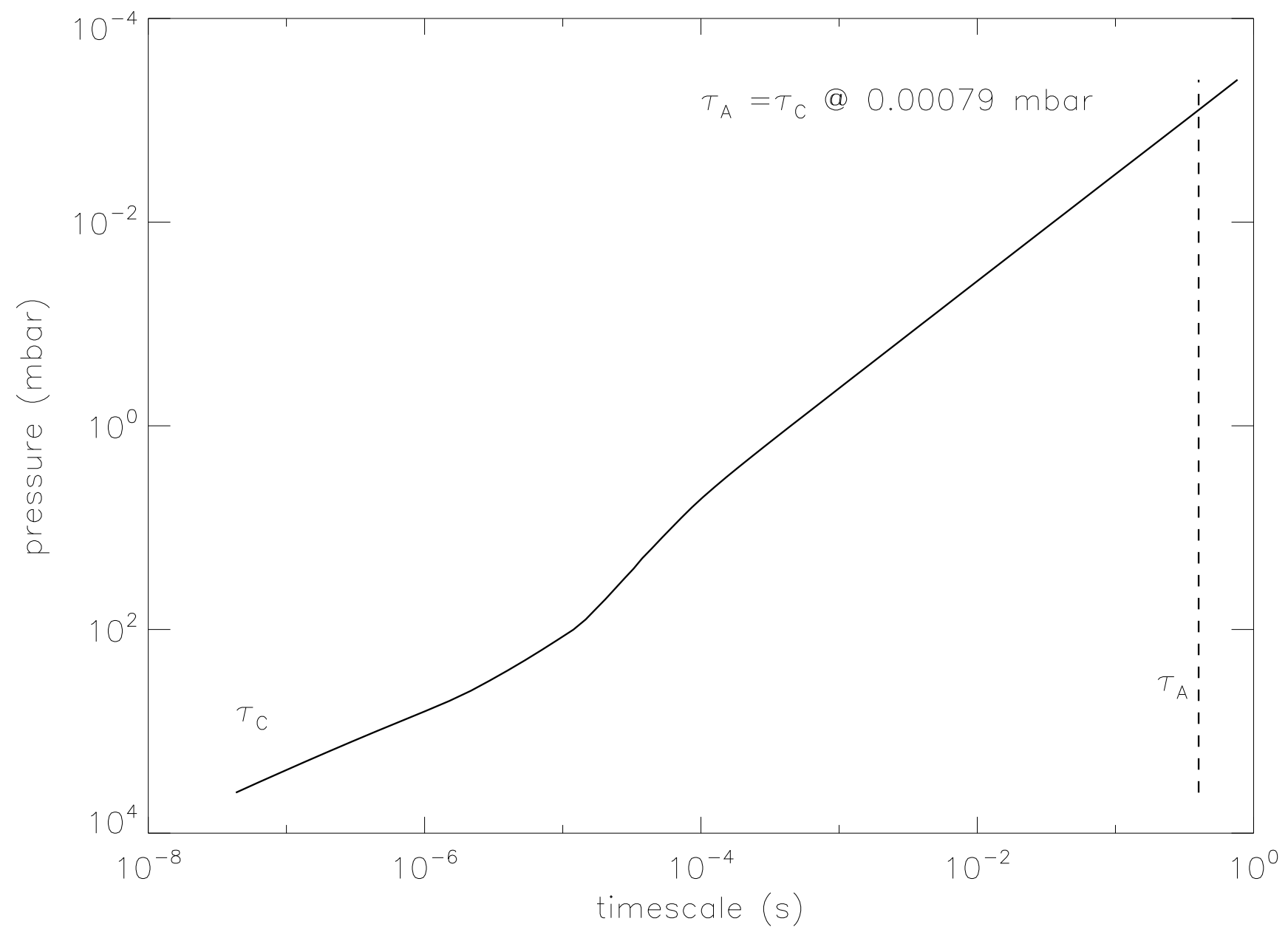

629

Nixon et al. Figure 7 
(a) Temperature: Voyager/IRIS
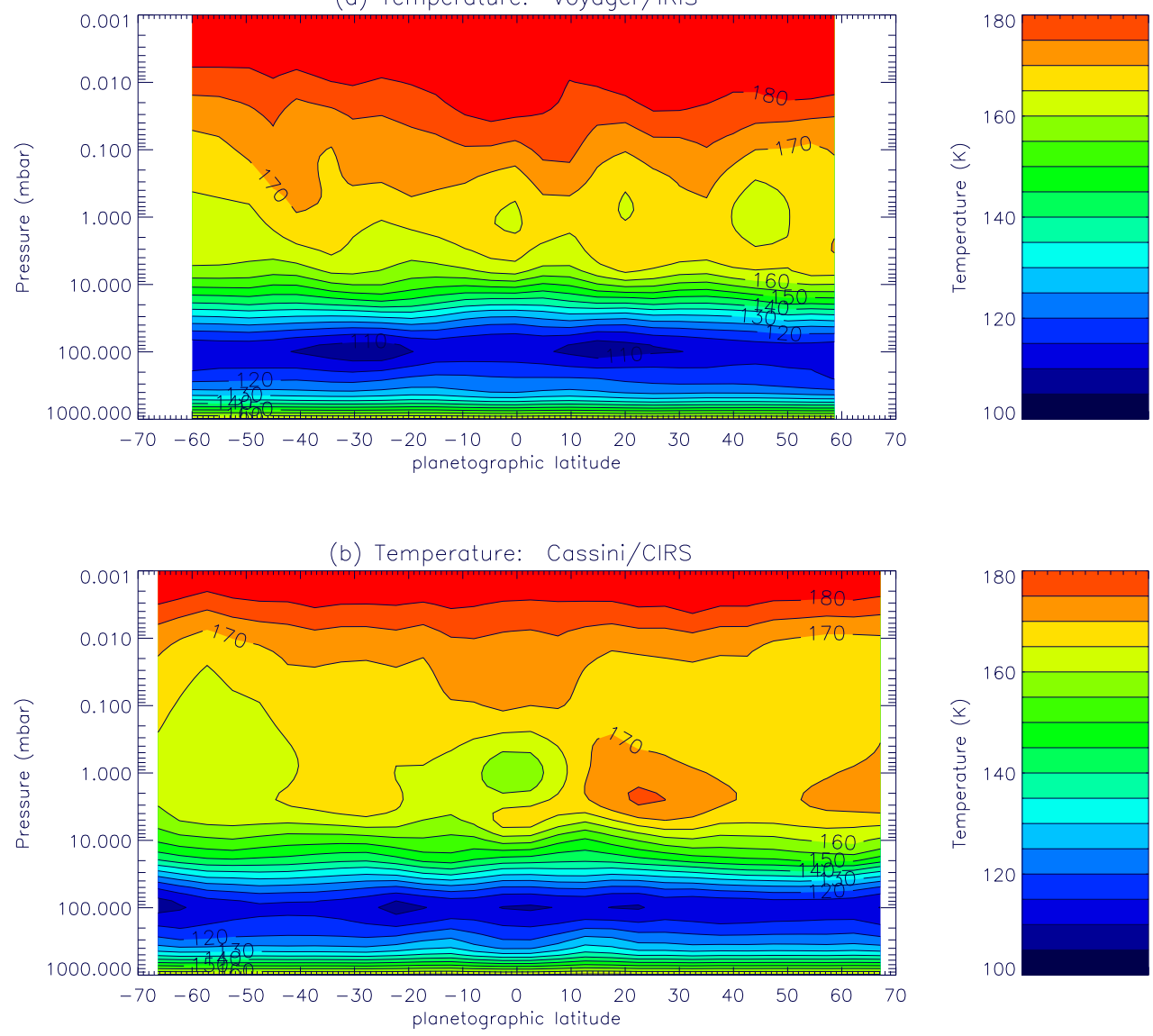

(c) Temperature: CIRS-IRIS Difference
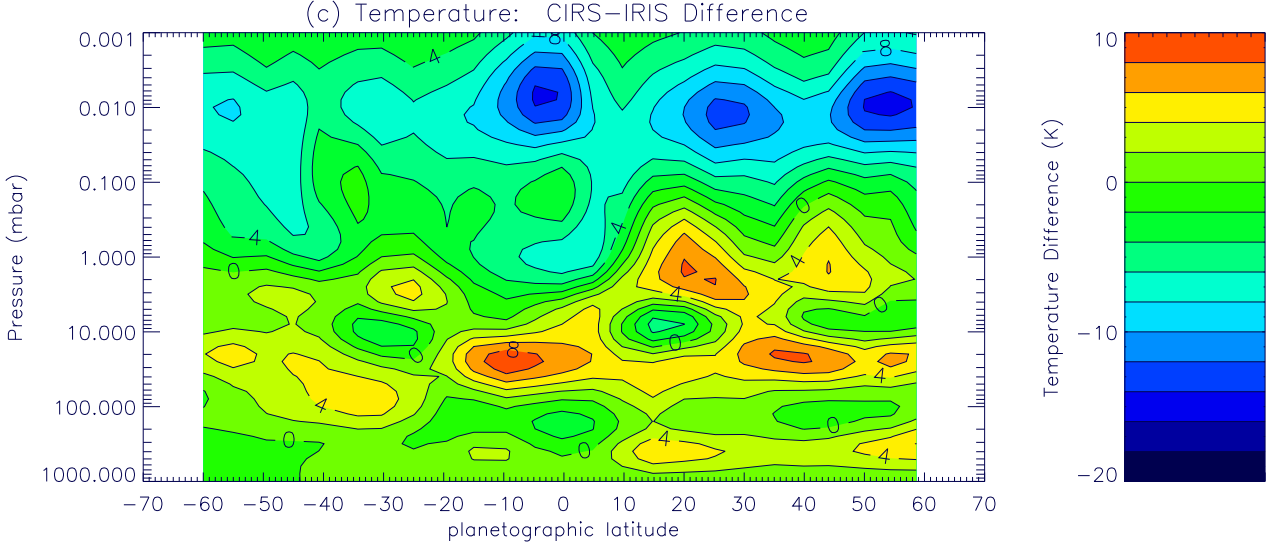

Nixon et al. Figure 8 

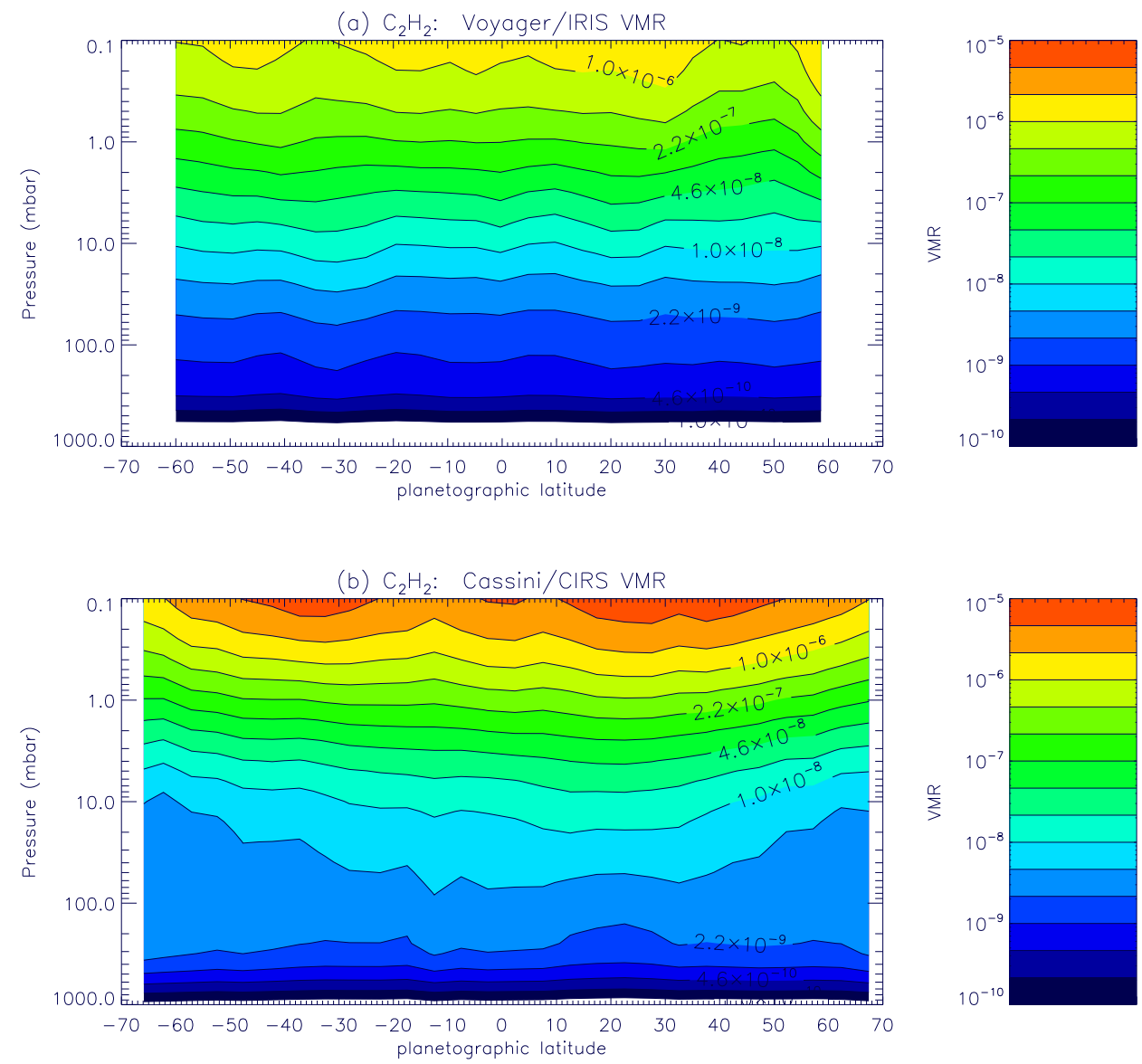

(c) $\mathrm{C}_{2} \mathrm{H}_{2}$ : CIRS-IRIS difference in log VMR
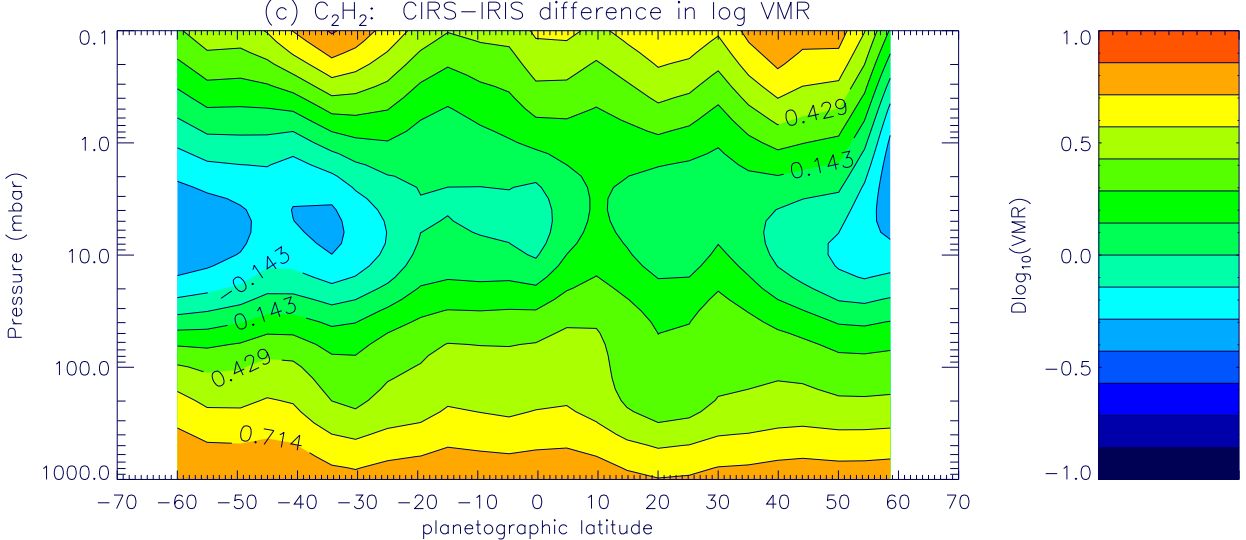

Nixon et al. Figure 9 
(a) $\mathrm{C}_{2} \mathrm{H}_{6}$ : Voyager/IRIS VMR

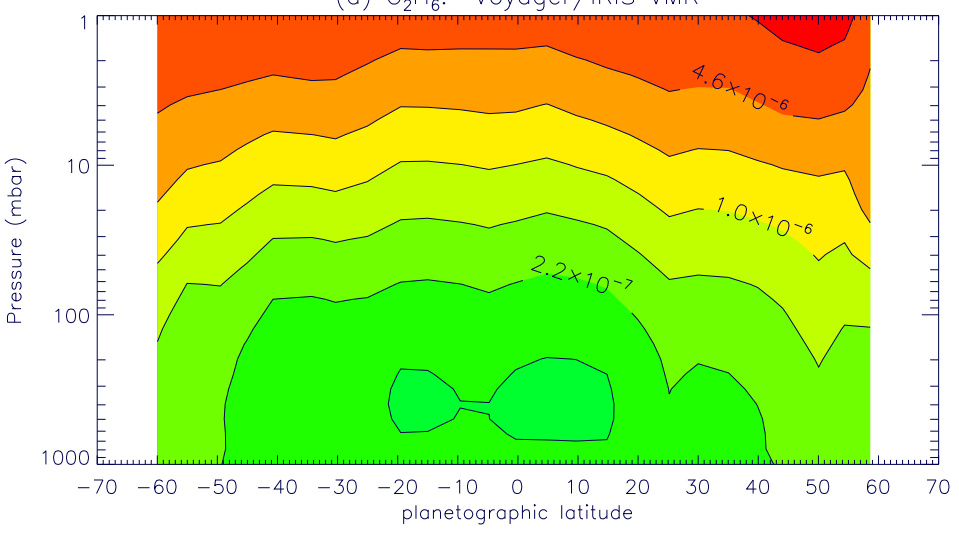

(b) $\mathrm{C}_{2} \mathrm{H}_{6}$ : Cassini/CIRS VMR

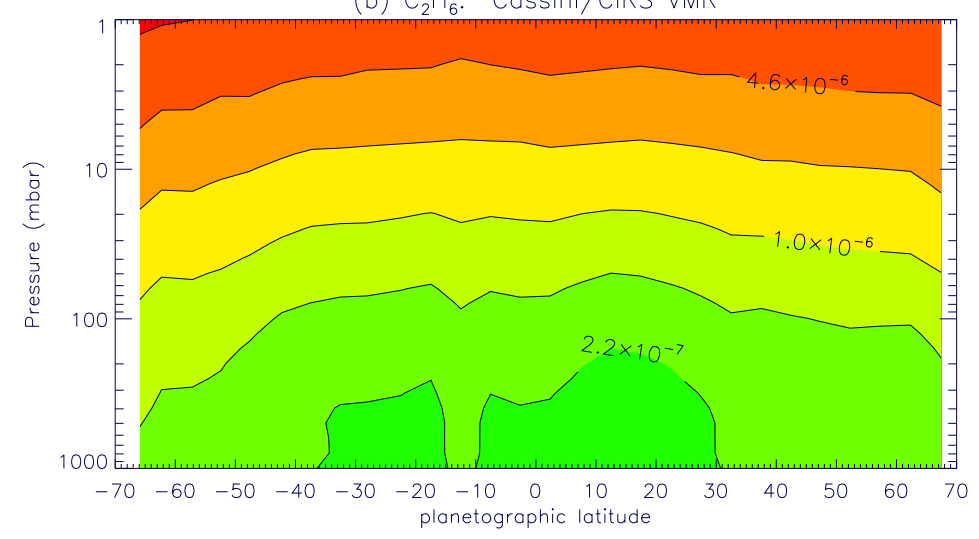

(c) $\mathrm{C}_{2} \mathrm{H}_{6}$ : CIRS-IRIS difference in log VMR

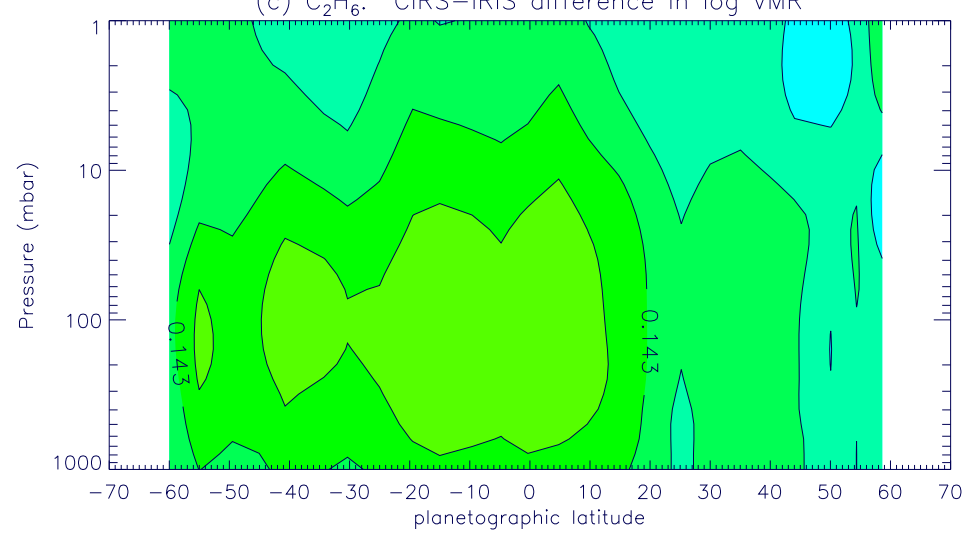

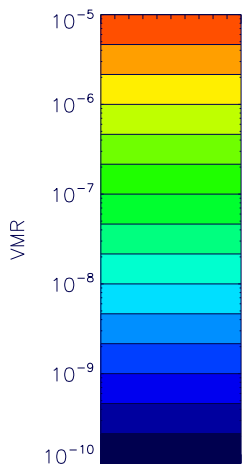
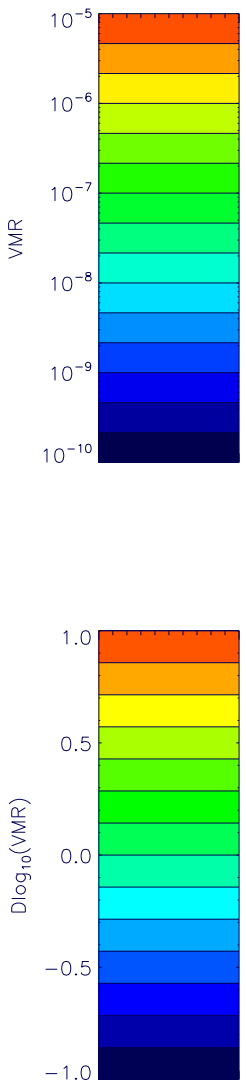
$\mathrm{C}_{2} \mathrm{H}_{2}$ VMR: CIRS 2010-2007 Retrieval Difference \%
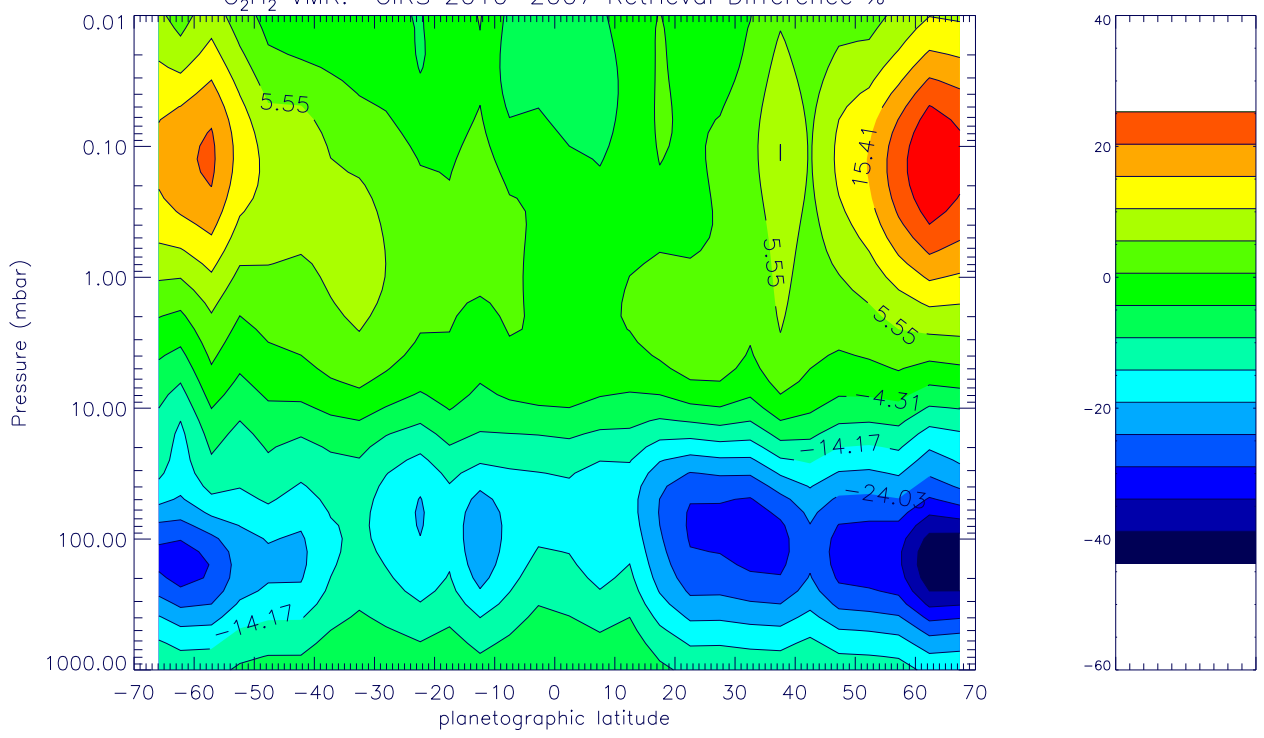

$\mathrm{C}_{2} \mathrm{H}_{6}$ VMR: CIRS 2010-2007 Retrieval Difference \%
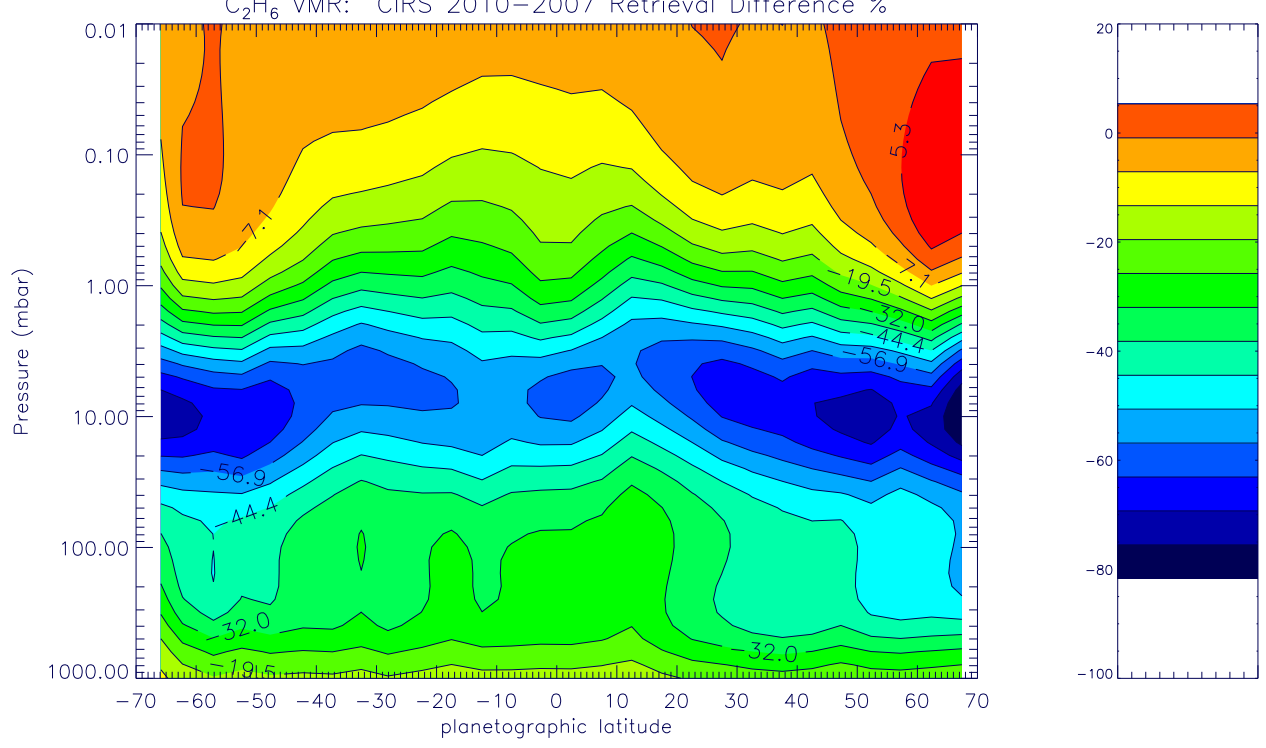

Nixon et al. Figure 11 


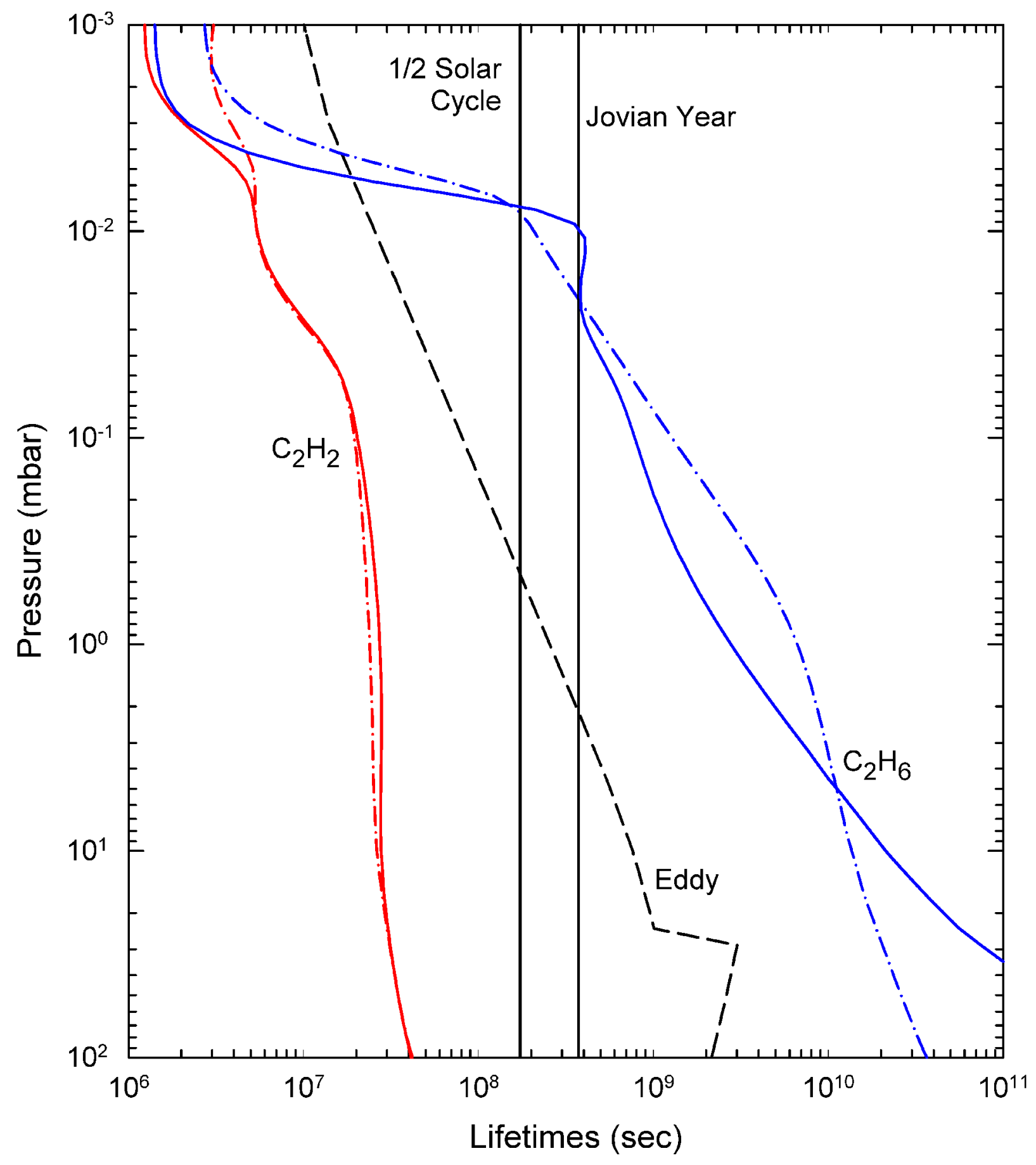

${ }_{64} \quad$ Nixon et al. Figure 12 